\title{
Differential prognostic impact of interleukin-34 mRNA expression and infiltrating immune cell composition in intrinsic breast cancer subtypes
}

\author{
Karin Zins $^{1}$, Gerwin Heller ${ }^{2,4}$, Mathias Mayerhofer ${ }^{1}$, Martin Schreiber ${ }^{3,4}$ and Dietmar \\ Abraham $^{1,4}$ \\ ${ }^{1}$ Division of Cell and Developmental Biology, Center for Anatomy and Cell Biology, Medical University of Vienna, A-1090 \\ Vienna, Austria \\ ${ }^{2}$ Department of Medicine I, Clinical Division of Oncology, Medical University of Vienna, A-1090 Vienna, Austria \\ ${ }^{3}$ Department of Obstetrics and Gynecology, Medical University of Vienna, A-1090 Vienna, Austria \\ ${ }^{4}$ Comprehensive Cancer Center Vienna, A-1090 Vienna, Austria \\ Correspondence to: Dietmar Abraham, email: dietmar.abraham@meduniwien.ac.at \\ Keywords: IL-34; CSF-1; gene expression; breast cancer patients; PAM50 subclasses \\ Received: September 15, $2017 \quad$ Accepted: April 05, $2018 \quad$ Published: May 01, 2018 \\ Copyright: Zins et al. This is an open-access article distributed under the terms of the Creative Commons Attribution License 3.0 \\ (CC BY 3.0), which permits unrestricted use, distribution, and reproduction in any medium, provided the original author and source \\ are credited.
}

\section{ABSTRACT}

Interleukin-34 (IL-34) is a ligand for the CSF-1R and has also two additional receptors, PTPRZ1 and syndecan-1. IL-34 plays a role in innate immunity, inflammation, and cancer. However, the role of IL-34 in breast cancer is still illdefined. We analyzed IL-34 mRNA expression in breast cancer cell lines and breast cancer patients and applied established computational approaches (CIBERSORT, ESTIMATE, TIMER, TCIA), to analyze gene expression data from The Cancer Genome Atlas (TCGA). Expression of IL-34 was associated with a favorable prognosis in luminal and HER2 but not basal breast cancer patients. Gene expression of CSF-1 and CSF-1R was strongly associated with myeloid cell infiltration, while we found no or only weak correlations between IL-34, PTPRZ1, syndecan-1 and myeloid cells. In vitro experiments showed that tyrosine phosphorylation of CSF-1R, ERK, and FAK and cell migration are differentially regulated by IL-34 and CSF-1 in breast cancer cell lines. Collectively, our data suggest that correlation of IL-34 gene expression with survival is dependent on the molecular breast cancer subtype. Furthermore, IL-34 is not associated with myeloid cell infiltration and directly regulates breast cancer cell migration and signaling.

\section{INTRODUCTION}

Breast cancer is the most common cancer among women worldwide and remains the leading cause of cancer death among females [1]. Its malignancy grade and patient prognosis is not only influenced by various mutations that occur in the tumor cell, but also by the tumor microenvironment (TME) [2].

The TME of breast cancer consists of a heterogeneous collection of cells and is enriched in highly active immune cells which, together with cytokines, play an important role in the regulation of breast cancer [3,
4]. The host immune response during breast cancer is dynamic and can affect tumor growth both in promotive and suppressive ways. Consequently, the prognosis of breast cancer patients is influenced by the density, composition and activity of the tumor immune infiltrate [3]. The addition of tumor-promoting inflammation as the seventh hallmark of cancer reflects the double-edged role of inflammatory processes in cancer progression [5].

Macrophages, the most prevalent immune cells in mammary tumors, exert a profound influence at each stage of cancer progression [4]. The majority of macrophages is regulated by colony-stimulating factor-1 (CSF-1), a 
key growth factor modulating macrophage proliferation, survival, and function through interaction with its receptor CSF-1R (CD115) [6]. CSF-1R is the product of the receptor tyrosine kinase $c-f m s$ proto-oncogene [7]. Our previous breast cancer studies found that CSF-1/CSF-1R signaling promotes tumor growth [8] [9, 10] and it has been demonstrated that CSF-1R blockade using antibodies reduced the number of resident tumor-associated macrophages (TAMs) in tumors [11].

The discovery in 2008 of IL-34 as a new ligand of CSF-1R [12] has changed the existing functional biological concepts for CSF-1/CSF-R1 [13]. Like CSF-1, IL-34 promotes the survival and proliferation of monocytes, as well as their differentiation into macrophages [12] and both cytokines can polarize macrophages into immunosuppressive M2 macrophages [14]. In addition, IL-34 has been shown to be involved in areas as diverse as neuronal protection, autoimmune diseases, infection, cancer, degenerative bone diseases and immune tolerance [15].

Several studies have shown a correlation between high IL-34 expression level and tumor development [15]. A study in giant cell tumors of bone has revealed that the pathogenesis results directly from the supporting action of IL-34 on osteoclastogenesis [16]. In osteosarcoma, IL-34 has been shown to be rather involved in TAM recruitment [17]. IL-34 produced by cancer cells, has also been identified as a driver of chemoresistance [18]. Cytotoxic therapies have been shown to induce the production of IL-34 in breast cancer [19]. In hepatocellular carcinoma patients, high IL-34 levels have been associated with a poor prognosis, with shorter overall survival (OS) and time to recurrence [20].

However, IL-34 signaling cannot be considered as a simple equivalent of CSF-1/CSF-1R signaling. Recent studies have demonstrated that IL-34 also binds to other receptors, the receptor-type protein-tyrosine phosphatase zeta (PTPRZ1)[21] and syndecan-1 (CD138) [22], increasing the complexity. These findings suggest that IL-34 may also exert specific functions independently of the CSF-1R. Activation of the cell surface chondroitin sulfate (CS) proteoglycan PTPRZ1 leads to increased tyrosine phosphorylation of several signaling pathways and is upregulated in many human cancers, such as lung cancer, prostate cancer, and glioma, regulating cancer cell migration and metastasis [23-25]. IL-34 binding to syndecan-1 modulates the IL-34-induced CSF-1R signaling pathways, and IL-34 induces the migration of monocytes and macrophages in a syndecan-1-dependent manner [22]. Syndecan-1 is a cell surface heparin sulfate proteoglycan, which is expressed by many cancers [26]. In breast cancer, increased cell-membrane syndecan-1 levels are found [27] and it is associated with high-grade tumors [28].

Despite the known expression of CSF-1 and CSF$1 \mathrm{R}$ in human breast cancer and their clear therapeutic potential, the role of IL-34 remains unclear. Here, we measured the levels of IL-34 in breast cancer patients using qRT-PCR and assessed the association of IL-34 expression with breast cancer outcome. To explore their potential biological role, we studied the association between IL-34, CSF-1 and their receptors with immune cell infiltration based on the breast cancer dataset of The Cancer Genome Atlas (TCGA). We report that IL34 expression is associated with differential outcome in intrinsic breast cancer subtypes. Our in vitro experiments provide evidence that IL-34 regulates cancer cell migration and mediates signaling in human breast cancer cells.

\section{RESULTS}

\section{IL-34 gene expression in normal and tumor tissue}

We analyzed differential IL-34 gene expression of RNA-seq data from normal tissues and tumor tissues using data generated by The Cancer Genome Atlas (TCGA). Summary of the distributions of the gene expression values were presented by boxplots in Figure 1A with the median, spread and outliers showing for each gene. IL-34 expression was distinctly separated between the normal and tumor tissues. In normal tissue, highest median IL34 levels were found in normal breast tissue. In breast cancer tumors abundant IL-34 expression variations were observed indicating that different gene expression patterns may exist in breast cancer tissues.

\section{IL-34 is differentially expressed in human breast cancer cell lines}

These data, however, could not address the question of whether cancer cells contribute to expression of IL-34. To analyze the expression of IL-34 by cancer cells, we examined IL-34 expression in 14 breast cancer cell lines and 4 normal breast epithelial cell lines. Quantitative qRT-PCR showed detectable levels of IL-34 mRNA in different cancer cells with some variations. Basal-like cell lines $(n=6)$ showed higher IL-34 expression levels than HER2-type cell lines $(n=3)$, luminal cell lines $(n=5)$, and normal cell lines $(n=4)$. IL-34 expression was similar between luminal and HER 2 cell lines, but showed IL-34 downregulation when compared to normal breast cancer cell lines (Table 1, Figure 1B). These observations suggest that IL-34 expression in breast cancer cells may differ depending on their molecular subtype.

\section{Association of IL-34 expression with clinical and histopathological characteristics of breast cancer patients}

Next, we asked whether IL-34 expression could be detected in primary human breast cancers. We quantified 
relative IL-34 mRNA expression in primary tumor tissue samples of 75 patients by qRT-PCR and searched for correlations between IL-34 mRNA expression and clinical and histopathological characteristics of breast cancer patients. As shown in Figure 2A, significantly elevated mean IL-34 mRNA levels were associated with an age $\geq 55$ years $(p=0.002)$ and post-menopause $(p=0.007)$. No correlation was found with tumor size, pathological type, tumor stage, tumor grade, lymph node status, estrogen receptor (ER) status, progesterone receptor (PR) status, HER2 status, and p53 status. Regarding the molecular subtypes, we observed the lowest IL-34 levels in luminal B cases. IL-34 levels in luminal A, HER-2 and basal-like cases were lower as compared to normal-like cases ( $p=0.005$, ANOVA), a similar pattern to the results of our analysis of breast cancer cell lines (Table 1 and Figure 1B; see above). Based on the mean $\mathrm{Ct}$ (cycle threshold) as a relative measure of the concentration of target in the PCR reaction, IL-34 gene expression was lower in cancer cell lines (mean Ct 30.94) as compared to our tumor samples (mean Ct 26.35) and normal tissue (mean Ct 26.26).

These data suggest that IL-34 expression varies significantly among different molecular subtypes of breast
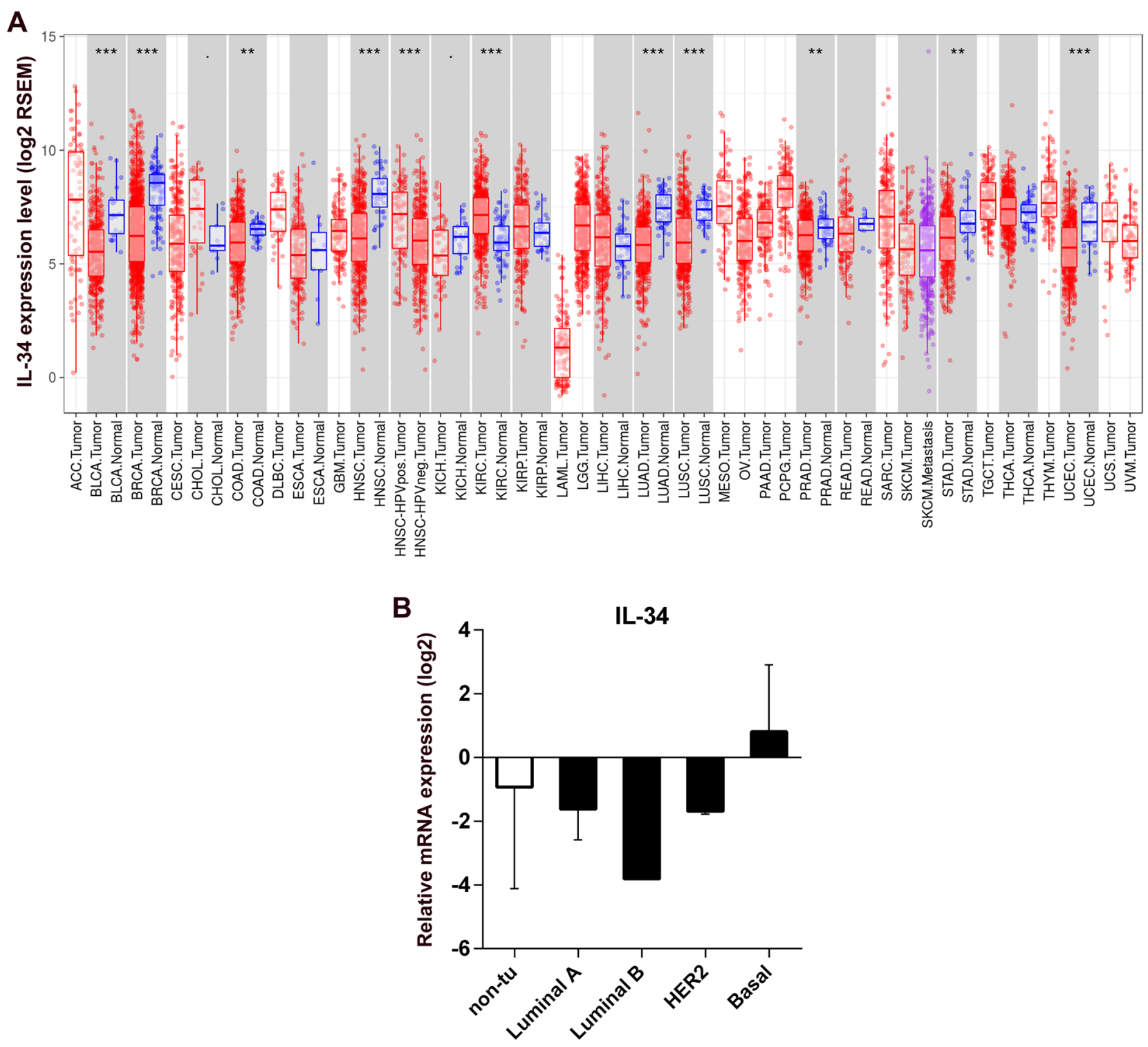

Figure 1: IL-34 mRNA expression in normal tissue, cancerous tissue, and breast cancer cell lines. (A) RNA expression overview shows RNA-seq data from The Cancer Genome Atlas (TCGA). Datasets of normal and cancerous human tissues were obtained from the TCGA database. Boxplots show the distributions (median, spread and outliers) of the IL-34 mRNA levels (log2) by the RNAseq by Expectation-Maximization (RSEM) normalization across normal and cancerous tissue. (B) IL-34 mRNA expression across molecular subtypes of breast cancer cell lines and normal breast cell lines. IL-34 expression level reported as $\log 2$ values $+/-$ SD according to the molecular subtype of cell lines; non-tu, non-tumorigenic cell lines. 
Table 1: IL-34 mRNA expression in a panel of human breast cancer cell lines

\begin{tabular}{|c|c|c|c|c|c|c|c|c|}
\hline Cell line & Cell type & $\mathbf{E R}^{*}$ & $\mathbf{P R}^{*}$ & HER2* & Vimentin* & N-cad ${ }^{*}$ & $\begin{array}{c}\text { IL-34 } \\
\log 2\end{array}$ & Subtype* \\
\hline HMEC & normal & & & & & & 3,16 & \\
\hline Hs 578Bst & normal & & & & & & $-3,80$ & \\
\hline MCF 10A & $\mathrm{F}$ & & & & & & $-3,08$ & \\
\hline MCF $10 \mathrm{~F}$ & $\mathrm{~F}$ & & & & & & 0,00 & \\
\hline MCF7 & tumor & + & + & - & - & - & $-2,62$ & Luminal A \\
\hline ZR-75-1 & tumor & + & + & - & - & & $-0,82$ & Luminal A \\
\hline $\mathrm{T}-47 \mathrm{D}$ & tumor & + & + & - & - & & $-2,28$ & Luminal A \\
\hline CAMA-1 & tumor & + & + & - & - & & $-0,76$ & Luminal A \\
\hline BT-474 & tumor & + & + & + & - & & $-3,81$ & Luminal B \\
\hline SK-BR-3 & tumor & - & - & + & - & - & $-1,62$ & HER2 \\
\hline AU565 & tumor & - & - & + & & & $-1,75$ & HER2 \\
\hline MDA-MB-453 & tumor & - & - & + & - & - & n.a. & HER2 \\
\hline MDA-MB-231 & tumor & - & - & - & + & - & $-0,76$ & Basal \\
\hline MDA-MB-468 & tumor & - & - & - & - & & 1,47 & Basal \\
\hline CAL-51 & tumor & - & & - & & & $-1,78$ & Basal \\
\hline HCC 1143 & tumor & & & - & & & 3,74 & Basal \\
\hline HCC1937 & tumor & - & - & - & & & 2,42 & Basal \\
\hline Hs $578 \mathrm{~T}$ & tumor & - & - & - & + & + & $-0,22$ & Basal \\
\hline
\end{tabular}

F, fibrocystic disease; ER, estrogen receptor; PR, progesterone receptor; HER2, human epidermal growth factor receptor-2; N-cad, N-cadherin IL-34, interleukin-34; normal, untransformed human mammary epithelial cells; n.a., not applicable.

"Determined from references [65-70].

cancer and that cancer cells only partially contribute to IL34 gene expression levels.

\section{Association of IL-34 expression with breast cancer prognosis}

Detailed follow-up records were available for our 75 patients. We subjected these patients to KaplanMeier analyses of the overall (OS), disease-free (DFS), and metastasis-free survival (MFS), comparing IL34-high patients with IL-34-low patients (Figure 2B). Unexpectedly, IL-34-high patients exhibited a better prognosis. Patients with a high IL-34 expression showed a significantly better OS $(p=0.036)$ than IL-34-low patients (Figure 2B). Likewise, high IL-34 expression had a significant impact on DFS and MFS as well. High IL34 expression was associated with a significantly better prognosis in both, the analyses of the DFS $(p=0.025)$ and the MFS $(p=0.022)$ (Figure 2B). In conclusion, patients with a high relative IL-34 mRNA expression exhibited increased survival and better prognosis.

\section{Association of IL-34 expression with breast cancer prognosis is dependent on the molecular subtype}

To further elucidate the relationship between IL-34 and breast cancer, we used breast cancer data generated by The Cancer Genome Atlas (TCGA). The median IL34 expression was correlated with OS of patients (median follow-up time: 671 days). Kaplan-Meier survival curves generated for IL-34 were split into high (top 50\%) and low (bottom 50\%) IL-34 expression, as shown in Figure $3 \mathrm{~A}$. These curves showed that high IL-34 expression was correlated with better outcome (log-rank $p=0.0064$ ) confirming data from our own patient data set.

We then investigated whether IL-34 expression differs between distinct molecular breast cancer subtypes and if IL-34 expression is associated with OS in these subtypes. Analysis of TCGA breast cancer RNA-seq data sets showed that IL-34 expression was lowest in luminal B subtype ( $p$ $<0.0001$ vs. normal). IL-34 levels in luminal A and HER2 subtypes were also lower as compared to normal breast 
tissue ( $p<0.0001$ vs. normal). In contrast, basal-like cases showed the highest IL-34 expression amongst all subtypes ( $p<0.0001$ vs. other subtypes; ns. vs. normal) (Figure 3B). These data are in accordance with findings of our own patient dataset, showing that IL-34 gene expression differs strongly between breast cancer subtypes.
Kaplan-Meier OS analyses of patients split by molecular subtype and classified as belonging to IL34 high or low showed significant survival differences (Figure 3C). Patients belonging to the luminal A subtype did not reveal a significant association between IL-34 expression and survival. Luminal B subtype patients
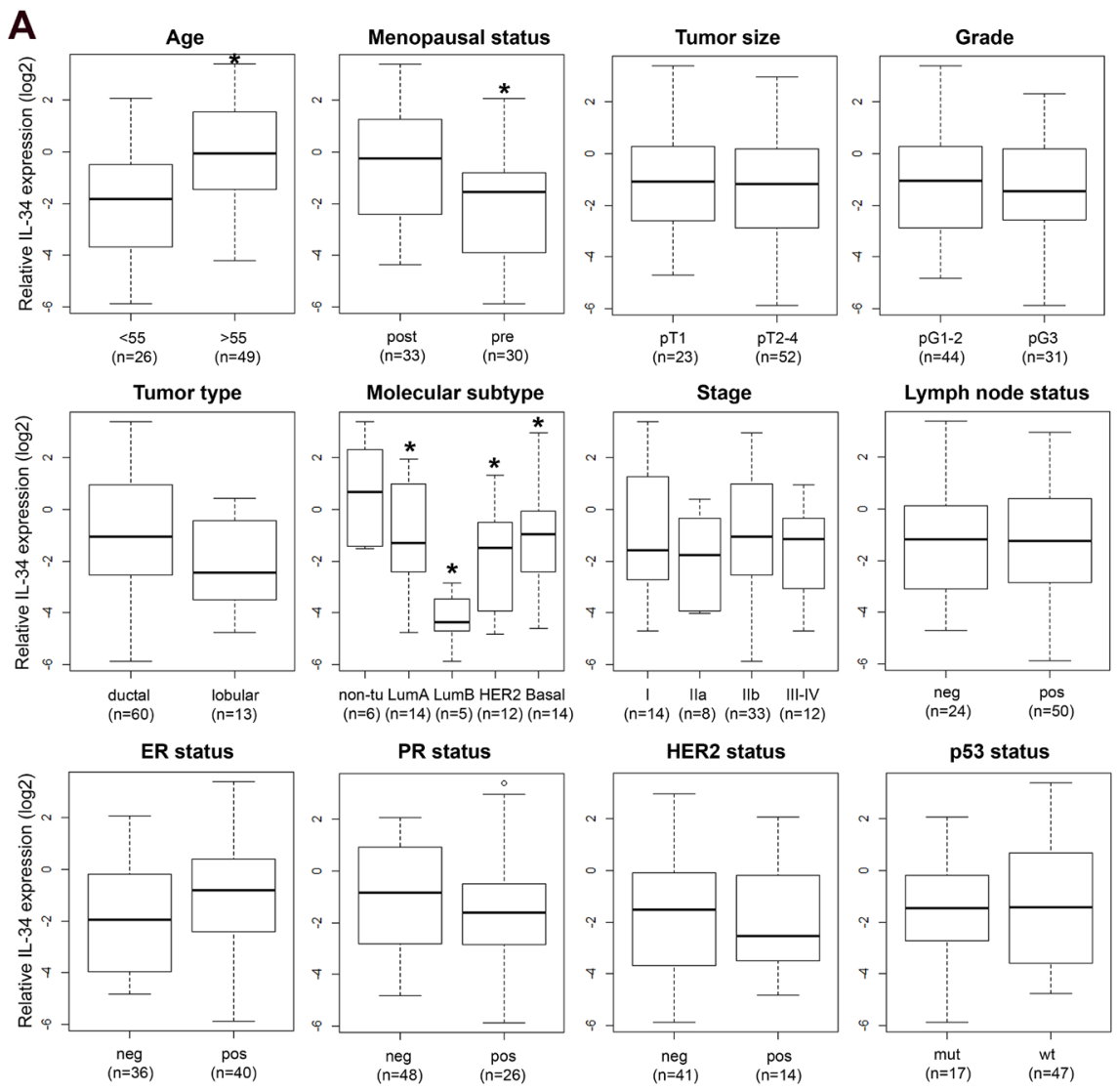

B
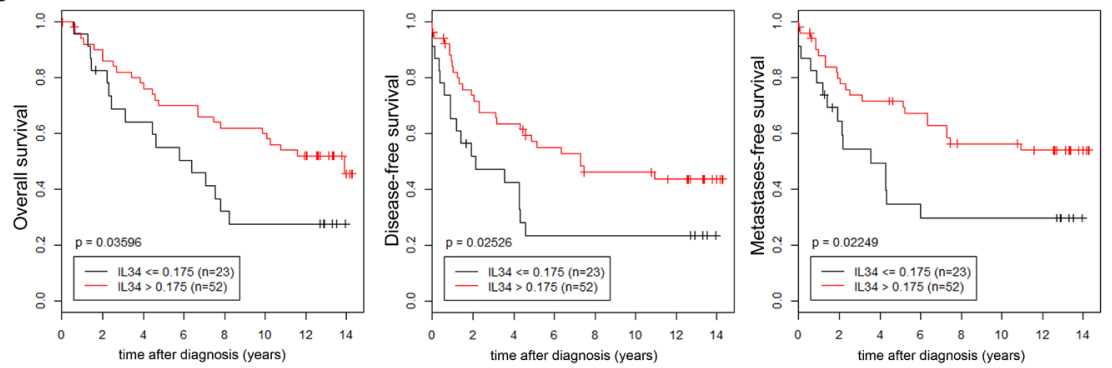

Figure 2: (A) IL-34 mRNA expression in breast tumors. Association of relative IL-34 mRNA expression (log2) with established clinical and histopathological parameters was analyzed in breast tumors. Boxplots of IL-34 expression in patients with an age at breast cancer onset of $<55$ vs. $\geq 55$ years ( $\left.{ }^{*}, p=0.002\right)$, in pre- vs. post-menopausal patients ( $\left.{ }^{*}, p=0.007\right)$, in pT1 vs. pT2-4 breast tumors, in grade $1-2$ vs. 3 breast tumors, IL-34 expression in ductal vs. lobular tumor type, in normal breast tissue (non-tumorous; non-tu) vs indicated molecular breast cancer subtypes $\left({ }^{*}, p=0.005\right.$, ANOVA), in patients with the indicated tumor stages, in breast tumors from patients with a negative (neg, pN0) vs. a positive (pos, $\mathrm{pN}+$ ) lymph node status, in estrogen receptor (ER) neg vs. pos tumors, in progesterone receptor (PR) neg vs. pos tumors, in HER2 neg vs. pos tumors, and in p53 mutant (mut) vs. wildtype (wt) tumors. Numbers in parentheses indicate the number of patients in each group. All $p$-values were determined via unpaired, two-sided $t$-tests except in molecular subtype and stage (ANOVA); neg, negative; pos, positive. Molecular subtype based on expression of the PAM50 gene set [71], determined with Affymetrix U133 Plus 2.0 GeneChips. (B) Association of IL-34 expression with survival of breast cancer patients. Kaplan-Meier analyses of the overall (left), disease-free (center) and metastasis-free survival (right) in breast cancer patients $(n=75)$ are shown. Patients were stratified into two groups according to IL-34 high and IL-34 low expression levels. 
showed a significantly better survival when IL-34 was high (log-rank $p=0.0086)$. Similarly, in the HER2 subtype high IL-34 expressing patients had a longer OS (log-rank $p=0.0268$ ). In contrast, the basal subgroup revealed an association between IL-34-high expression and poor survival of breast cancer patients, however, this difference did not reach statistical significance (log-rank $p=0.0694$ ). Thus, IL-34 mRNA expression levels are associated with differential prognosis in PAM50 breast cancer subtypes in the TCGA dataset.
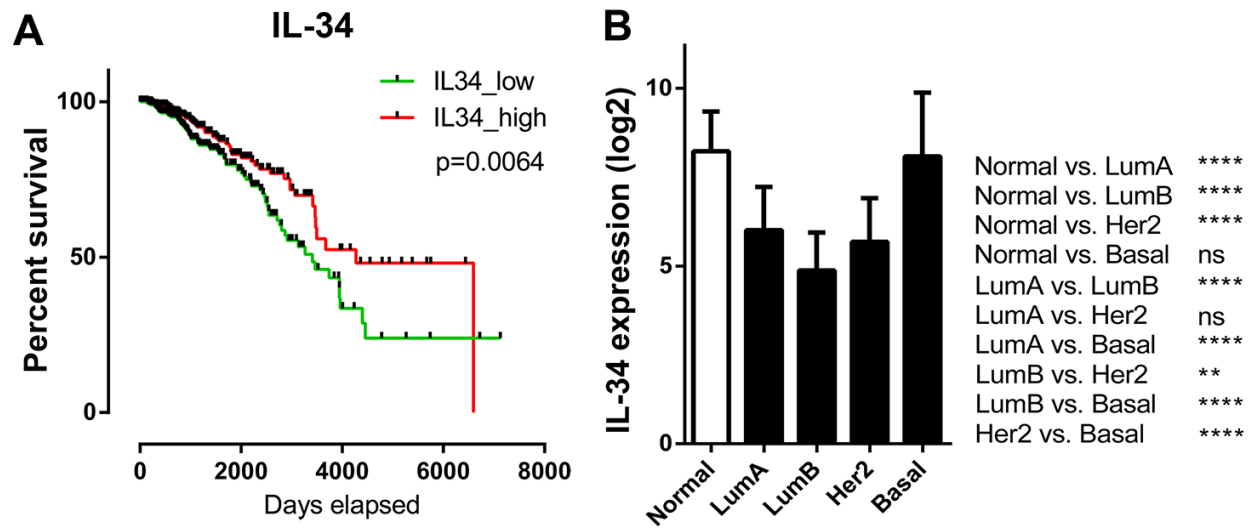

C

PAM50 subclasses

Luminal A

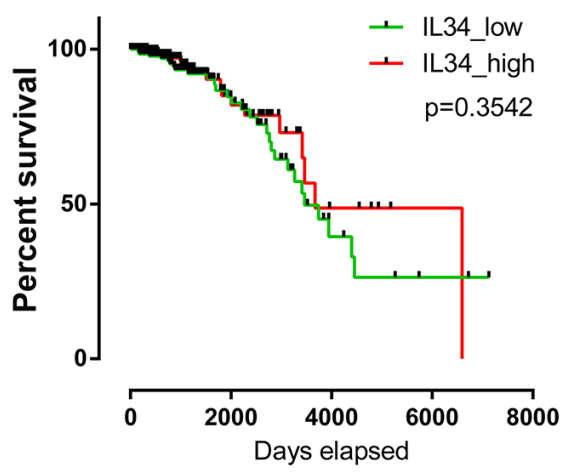

HER2

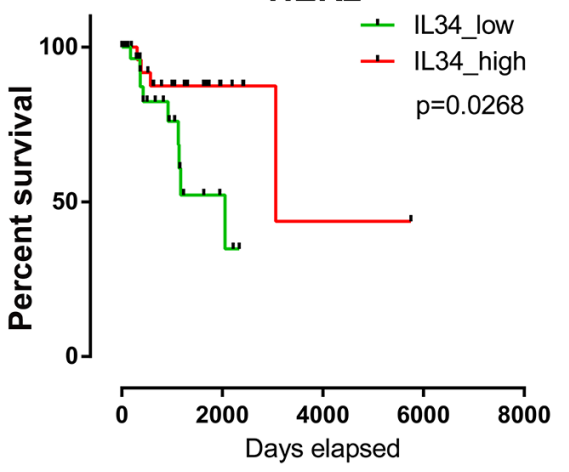

Luminal B

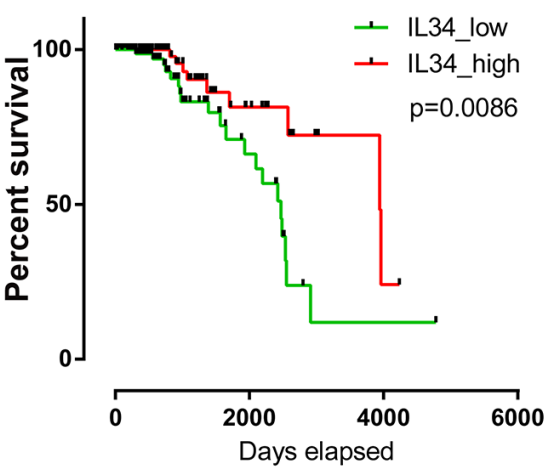

Basal

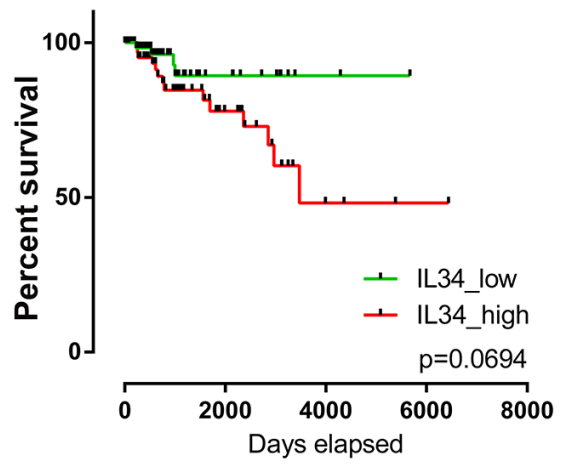

Figure 3: IL-34 expression and overall survival across molecular subtypes of breast cancer. (A) Kaplan-Meier plots of overall survival in IL-34-high and IL-34-low expressing TCGA BRCA patients ( $\mathrm{n}=1056)$. Median IL-34 expression was used as cut-off for group separation. Log rank tests were calculated. (B) IL-34 mRNA expression in normal breast tissue and in PAM50 breast cancer subclasses. The bar graph shows the IL-34 mRNA levels ( $\log 2)$ across normal breast tissue $(\mathrm{n}=113)$ and the molecular subtypes of breast cancer (luminal A, $\mathrm{n}=412$; luminal B, $\mathrm{n}=188$; HER2-enriched, $\mathrm{n}=64$; basal, $\mathrm{n}=140$ ) of the TCGA BRCA dataset. Kruskal-Wallis and Dunn's multiple comparison tests were calculated. Error bars indicate standard deviations. ${ }^{*}, p<0.05 ;^{* *}, p<0.01 ;^{* * *}, p<0.001 ;^{* * * *}, p<$ 0.0001. (C) Kaplan-Meier plots of overall survival in IL-34-high and IL-34-low expressing TCGA BRCA patients stratified by PAM50 subclasses (luminal A, $n=412$; luminal $B, n=188$; HER2-enriched, $n=64$; basal, $n=140$ ). Median IL-34 expression was used as cut-off for group separation. Log rank tests were calculated. 


\section{Association with overall survival: Expression of CSF-1 and IL-34-receptors}

There is not necessarily a sole factor mediating the biological activities of IL-34, because, unlike CSF-1, IL34 binds not only to CSF-1R, but also to PTPRZ1 and syndecan-1 (Figure 4). Thus, we analyzed potential mRNA expression differences of CSF-1, CSF-1R, PTPRZ1, and syndecan-1 between breast cancer samples and normal breast tissue samples from the TCGA breast cancer dataset (Figure 5A). CSF-1 and CSF-1R mRNA expression in tumors (median: 9.02 and 9.97, respectively) was below levels of normal tissue (median: 10.21 and 10.5, respectively). However, the strongest downregulation of gene expression in tumors compared to normal breast tissues was found for PTPRZ1 (median: 3.18 vs. 8.21). In contrast, syndecan-1 mRNA expression was higher in primary breast tumors vs. normal tissue (median: 12.62 vs. 11.05; Figure 5A). All these differences were statistically highly significant. To evaluate if syndecan-1 gene expression is associated with the IL-34 axis, we examined correlations between syndecan-1 and IL-34, CSF-1, CSF-1R, and PTPRZ1 mRNA expression and found a weak positive correlation between syndecan-1 and IL-34 (Pearson correlation $\mathrm{r}=0.20, p<0.0001$; Supplementary Figure 1, Table 2). In contrast, the Pearson's correlation coefficients for CSF-1, CSF-1R, and PTPRZ1 were $0.01,0.09$, and 0.06 , respectively, indicating a lack of correlation with syndecan-1 (Supplementary Figure 1, Table 2).

Analysis of CSF-1 and CSF-1R expression in molecular breast cancer subtypes revealed generally lower levels for both when compared to normal tissue. Differences in mRNA levels related to normal tissue were more pronounced for PTPRZ1, similar to IL-34. Luminal and HER-2 subtypes showed clearly diminished levels. Basal subtype PTPRZ1 levels were significantly higher in comparison to luminal and HER-2 subtypes, although these patients also express PTPRZ1 at levels below normal PTPRZ1 expression. In contrast, syndecan-1 levels were significantly higher in all molecular subtypes than the respective normal tissue values (Figure 5B).

Next, we examined the prognostic effect of CSF1, CSF-1R, PTPRZ1, and syndecan-1 expression in the breast cancer TCGA dataset by generating Kaplan-Meier survival curves split in high (top 50\%) and low (bottom $50 \%$ ) gene expression (Figure 5C). In contrast to IL-34, high expression of CSF-1 (log-rank $p=0.5438)$ and CSF-1R (log-rank $p=0.1806$ ) was associated with worse outcome during the follow-up period. These data, although not reaching statistical significance, are supported by previous observations showing that high expression of CSF-1/CSF-1R in neoplastic epithelial breast cancer correlates with a poor prognosis [29-31]. On the other hand, high expression of PTPRZ1 was associated with better outcome $(\log$-rank $p=0.0165)$, whereas low expression of syndecan-1 was found to be associated with better outcome (log-rank $p=0.014)$. These data suggest differential expression and survival statistics for the IL-34 receptors CSF-1R, PTPRZ1, and syndecan-1.

We subsequently examined the prognostic effect of IL-34/CSF-1R, IL-34/PTPRZ1, and IL-34/syndecan-1 expression ratios by generating Kaplan-Meier survival curves split in high (top 50\%) and low (bottom 50\%) IL-34/receptor ratio (Figure 6A). A high IL-34/CSF-1R ratio (log-rank $p=0.0037)$ was associated with better outcome. Likewise, a high IL-34/syndecan-1 ratio showed positive correlation with better survival, but did not reach significance here (log-rank $p=0.0713)$. A high IL-34/ PTPRZ1 ratio on the other hand correlated with poor prognosis $(\log$-rank $p=0.0042)$.

Further analysis of IL-34/receptor ratios in molecular subtypes showed that the IL-34/CSF-1R mRNA expression ratio was significantly lower in luminal and HER-2 but not basal subtypes. The IL-34/syndecan-1 ratio was significantly decreased in all molecular subtypes in comparison with normal tissue, while the IL-34/PTPRZ1 mRNA expression ratio was significantly higher in all molecular subtypes (Figure 6B). These results show the complexity of IL-34/receptor mRNA ratios in molecular subtypes of breast cancer.

\section{IL-34, PTPRZ1, and syndecan-1 are not associated with myeloid cells in the breast cancer microenvironment}

Tumors are complex environments, composed of transformed cells as well as stromal cells and immune infiltrates and there is a great deal of evidence that points to the stroma and immune cells as major regulators of tumor progression. We used the ESTIMATE algorithm to correlate the extent of stromal cells with expression of IL-34, CSF-1, CSF-1R, PTPRZ1, and syndecan-1 in breast cancer tissue from the TCGA breast cancer dataset. The stromal score was strongly associated with CSF-1R levels and weakly with CSF-1 and syndecan-1 levels. IL34 showed only little and PTPRZ1 no association with the stromal score (Supplementary Figure 2, Table 3).

Immune cell subsets present in the microenvironment surrounding cancer cells include B cells, T cells, macrophages, neutrophils, and dendritic cells. We applied the TIMER tool to investigate tumor purity and the infiltrating immune cell landscape of breast cancer (B cells, CD4+ T cells, CD8+ T cells, neutrophils, macrophages and dendritic cells) in the context of mRNA expression of our target genes (Figure 7, Table 4, Supplementary Table 1). Notably, CSF-1 and CSF$1 \mathrm{R}$ shared the same immune cell profile, showing a clear association with neutrophils, dendritic cells, macrophages and CD4+ T-cell populations and to a lesser extent with CD8+ T cells and B cells. In contrast, IL-34 even showed a slight negative association with macrophages and little 
(neutrophils and dendritic cells) or no (B cells, CD8+ T cells) association with other immune cell populations. Only CD4+ T cells exhibited a weak positive correlation with IL-34. Little or no correlation was found between analyzed immune cell populations and both PTPRZ1 and syndecan-1. CSF-1, CSF-1R, and IL-34 were weakly negatively associated with tumor purity, while the lack of association between immune cell infiltration and gene expression of PTPRZ1 and syndecan-1 was also reflected by tumor purity values (Figure 7, Table 4, Supplementary Table 1).

These findings suggest that IL-34 and its receptors PTPRZ1 and syndecan-1 are not linked to myeloid cells, whereas the CSF-1/CSF-1R axis shows a strong correlation with myeloid cells in the tumor microenvironment.

\section{Differing association of macrophage subsets with IL-34 and CSF-1}

Despite the lack of a significant link between IL-34 and macrophages, we assessed the potential association between macrophage subsets and IL-34, CSF-1 and their receptors. We analyzed tumor-associated monocyte, differentiated M0 macrophage, as well as polarized M1 and M2 macrophage signatures in the breast cancer TCGA dataset using the TCIA database [32]. M0 macrophages are presumed naïve cells that have not been stimulated, whereas M1 or M2 macrophages received signals that promote activation and functional polarization [33]. The comparison revealed a weak positive association of IL34 and PTPRZ1 with M1 macrophages, while both were weakly negatively associated with M2 macrophages
(Figure 8A, Table 5, Supplementary Table 2). Little association with M1 macrophages was found for CSF1, CSF-1R, and PTPRZ1 and we found no relationship between M2 macrophages and CSF-1, CSF-1R, and syndecan-1 in the dataset. Furthermore, there was little positive correlation of CSF-1 with monocytes and of syndecan-1 with differentiated M0 macrophages. No significant correlation could be identified between the other investigated genes and monocytes or M0 macrophages (Figure 8A, Table 5, Supplementary Table 2).

In addition, we assessed the prognostic association of M1 and M2 macrophages in breast cancer by stratifying our population for M1 and M2 high/low. As expected, high numbers of tumor-associated M2 macrophages were found to predict worse outcomes than pro-inflammatory M1 macrophages (Figure 8B).

These findings indicate varying degrees of the relationship between macrophage subsets and IL-34 and CSF-1.

\section{M0, M1, and M2 macrophages stratified by PAM50 subtypes}

To gain a better understanding of associations between IL-34/CSF-1, their receptors and different macrophage subtypes, we analyzed M0, polarized M1 and M2 macrophage scores from TCIA database stratified by PAM50 subtypes. In addition, we analyzed stromal, immune, and ESTIMATE scores to assess the presence of infiltrating stromal and immune cells in tumor tissue using the TCGA gene expression data.

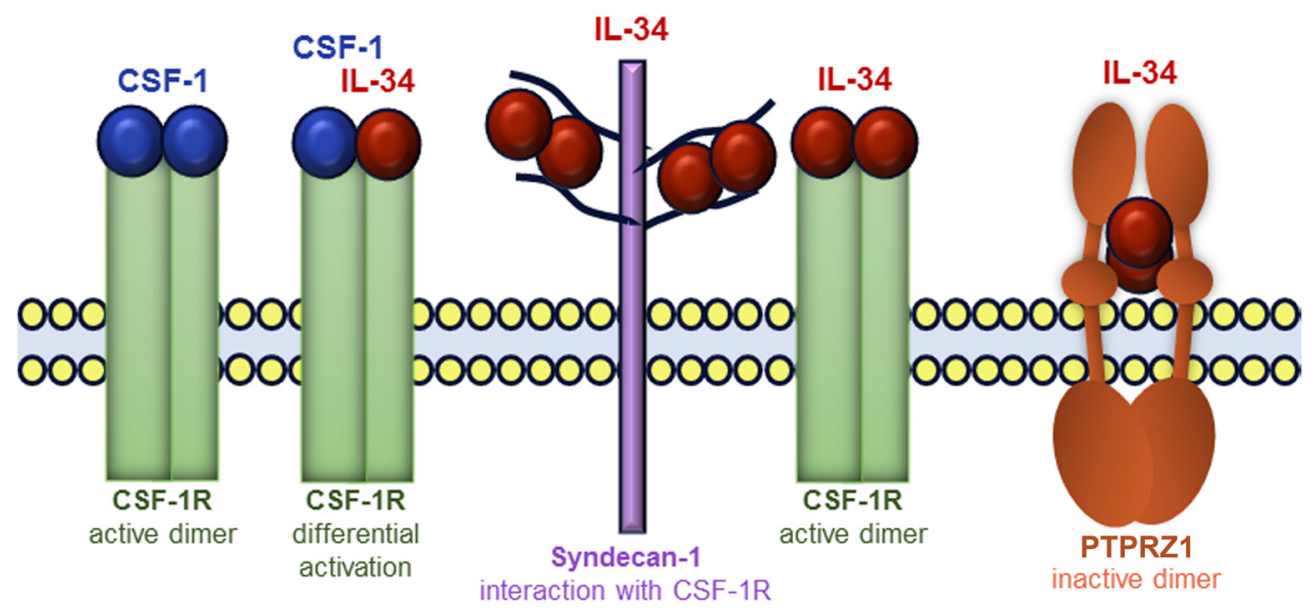

Cancer cell, Stromal cell, Immune cell

Figure 4: Schematic representation of IL-34 and CSF-1 receptors in tumor tissue consisting of cancer cells, stromal cells, and immune cells. IL-34 and CSF-1 bind to CSF-1R. Heteromeric CSF-1/IL-34 can also form, which may differentially regulate activation/localization of CSF-1R. Additionally, IL-34 can bind to syndecan-1, which then regulates CSF-1R activity. Finally, IL-34 also binds to PTPRZ1. 
A
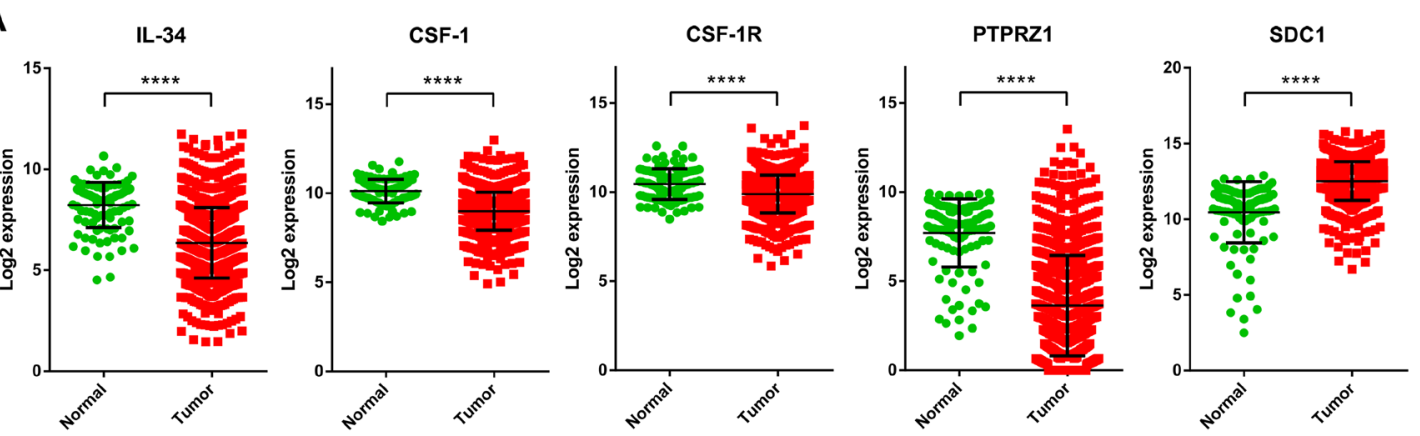

B
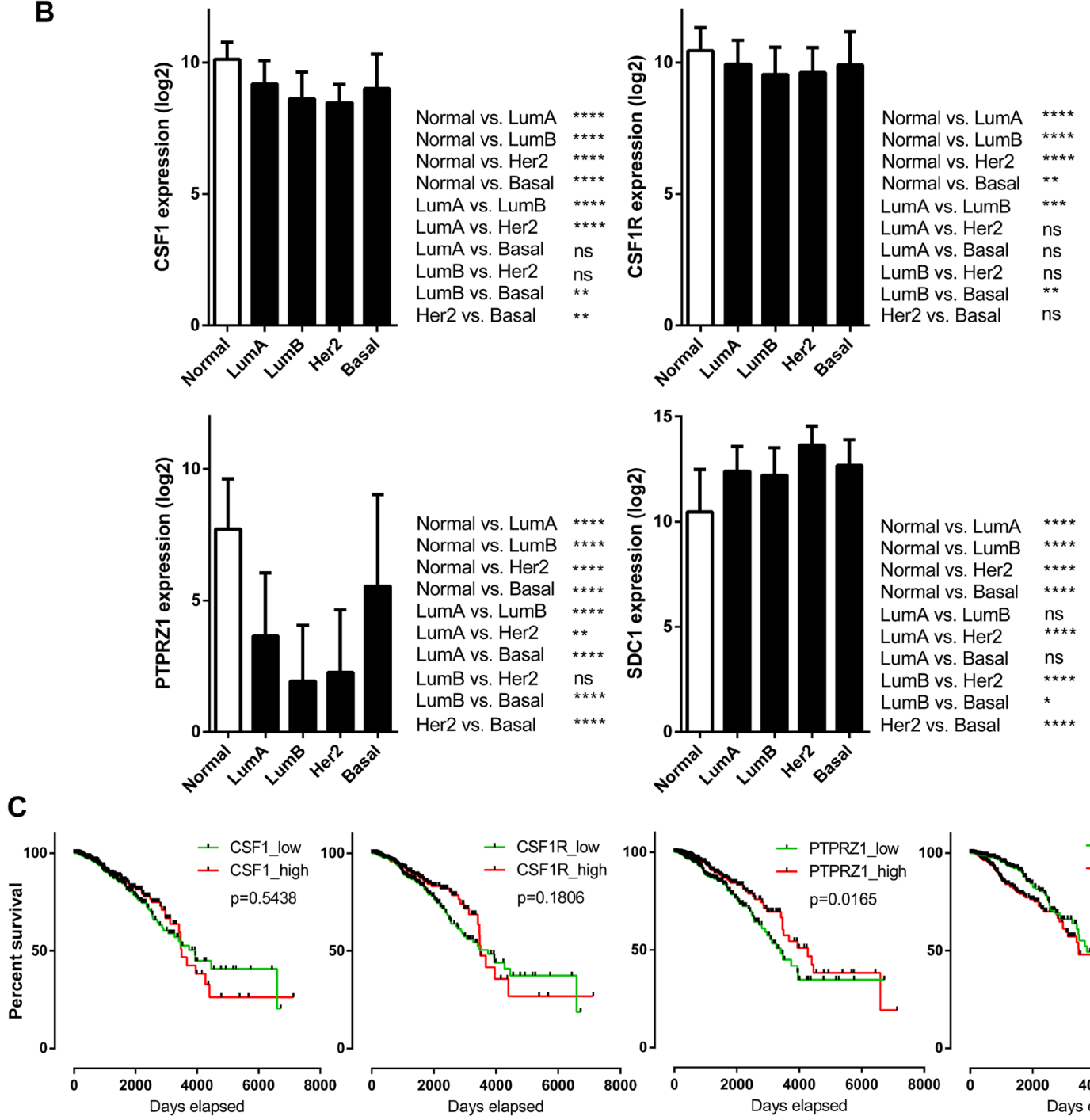

Normal vs. LumA $\quad * * * *$ Normal vs. LumB Normal vs. Her2

Normal vs. Basal LumA vs. LumB LumA vs. Her2 LumA vs. Basal LumB vs. Her2 LumB vs. Basal Her2 vs. Basal

Normal vs. LumB $* \star \star *$

Normal vs. Her2 ****

LumA vs. LumB $\quad * * *$

LumA vs. Basal

LumB vs. Her2 ns

Bs. Basal$$
\text { . }
$$ 
Table 2: Correlation between SDC1 mRNA and mRNA levels for IL-34, CSF-1, CSF-1R, and PTPRZ1

\begin{tabular}{ccccc}
\hline & IL-34 & CSF-1 & CSF-1R & PTPRZ1 \\
& $\mathbf{r}(\boldsymbol{p})$ & $\mathbf{r}(\boldsymbol{p})$ & $\mathbf{r}(\boldsymbol{p})$ & $\mathbf{r}(\boldsymbol{p})$ \\
\hline SDC1 & $\mathbf{0 . 2 0}(<\mathbf{0 . 0 0 0 1})$ & $0.01(\mathrm{~ns})$ & $0.09(0.003)$ & $0.06(0.053)$ \\
\hline
\end{tabular}

r, Pearson's correlation coefficient; $p, p$-value; ns, not significant. (TCGA BRCA dataset).

Table 3: Stromal score compared with gene expression

\begin{tabular}{lc}
\hline & Stromal sc \\
& $\mathbf{r}(\boldsymbol{p})$ \\
\hline IL-34 & $\mathbf{0 . 2 0}(<\mathbf{0 . 0 0 0 1})$ \\
CSF-1 & $\mathbf{0 . 4 6}(<\mathbf{0 . 0 0 0 1})$ \\
CSF-1R & $\mathbf{0 . 6 4}(<\mathbf{0 . 0 0 0 1})$ \\
PTPRZ1 & $\mathbf{0 . 0 9}(\mathbf{0 . 0 0 3})$ \\
SDC1 & $\mathbf{0 . 3 3}(<\mathbf{0 . 0 0 0 1})$ \\
\hline
\end{tabular}

Pearson's product-moment correlation of stromal cell infiltration and gene expression in the TCGA BRCA dataset. ESTIMATE algorithm was used to correlate the level of infiltrating stromal cells with in breast cancer tissues. Stromal sc, Stromal score; r, Pearson's correlation coefficient; $p, p$-value.

We observed considerable variation between gene expression, macrophage subsets, and scores, and many of these associations are statistically significant (Table 6, Supplementary Table 3, Supplementary Figure 3). Stratification for M0, M1 and M2 macrophage phenotype yielded a pattern, in which IL-34 expression correlated positively with M1 phenotype in luminal subtypes and was found to be generally negatively correlated with M2 macrophages, with the exception of basal subtype. Only little or no correlations with macrophage subsets were found for PRTPRZ1 expression. On the other hand, syndecan-1 showed a positive relationship was found between syndecan-1 and M0 and M2 macrophages in HER2 subtype, whereas no or little correlations were seen in other subtypes. Unexpectedly, both CSF-1 and CSF$1 \mathrm{R}$ expression correlated weakly with M1 macrophages in basal subtype, while no or little correlations were found in other subtypes.

By comparing stromal, immune and ESTIMATE scores in intrinsic breast cancer subtypes, we identified strong relationships of CSF-1 and CSF-1R to all scores (Table 6, Supplementary Table 3, Supplementary Figure 4). In contrast, correlation of IL-34 was weakly positive in luminal A and B subtypes, got lower in HER2 subtype and was lowest in basal subtype. A similar relationship was found between intrinsic subtype and syndecan-1. Syndecan-1 correlated positively with stromal and ESTIMATE score in luminal A and B subtypes, with stromal score in HER2 subtype, but no correlation was observed in basal subtype. However, syndecan-1 correlated only little or not with immune score in all subtypes. PTPRZ1 shows little or no correlation with any of these scores in all subtypes (Table 6, Supplementary Table 3, Supplementary Figure 4).

Together, these data demonstrate a subtype specific correlation pattern between IL-34, its receptors and macrophage subtypes. They also show a differential relationship between gene expression and stromal, ESTIMATE, and immune scores in intrinsic subtypes. Notably, IL-34 and its receptors PTPRZ1 and syndecan-1 showed no relationship to the analyzed scores in basal subtype.

\section{IL-34 and CSF-1 differentially regulate breast cancer cell migration and signaling}

To experimentally evaluate, whether IL-34 and CSF-1 directly regulate breast cancer cells depending on their subtype, we assessed the effect of recombinant IL-34 and CSF-1 on luminal-like MCF7, HER-2-positive SKBR-3, and basal type MDA-MB-231 breast cancer cells.

First, we compared IL-34,CSF-1, CSF-1R, PTPRZ1, and $S D C 1$ gene expression between human MCF7, SKBR-3 and MDA-MB-231 cancer cells in comparison to human THP-1 macrophages. Quantitative RT-PCR showed that IL-34 was expressed at low levels in all cell lines. A high CSF-1 mRNA level was only found in THP-1 macrophages. CSF-1R mRNA expression levels were much higher in THP-1 and SK-BR-3 cells as compared to MCF-7 and MDA-MB-231 cells. Notably, PTPRZ1 and syndecan-1 mRNA was expressed at high levels in SKBR-3 cells, while only low (MCF7 and MDA-MB-231 cells) or no expression (THP-1 cells) was found in other cell lines (Figure 9A). Together, these data indicate that breast cancer cells have a varying potential to respond to IL-34.

IL-34 is known to increase migration of monocytes and macrophages [22]. Here, we set out to evaluate the effects of IL-34 and CSF-1 on cancer cell migration in transwell assays. Migration of MCF7 cells was not affected by IL-34, whereas IL-34 stimulation significantly decreased migration of SK-BR-3 cells by $56 \%$. In contrast, IL-34 enhanced the ability of MDA-MB-231 cells to migrate by $64 \%$ relative to control cells. The effect of CSF-1 was quite different. CSF-1 stimulation significantly enhanced cell migration in MCF-7 breast cancer cells by 
$52 \%$, while no significant increases were observed for SKBR-3 (7\%; n.s) and MDA-MB-231 (10\%; n.s) relative to control cells (Figure 9B).

To address the role of CSF-1R in cancer cell migration, we pretreated cells with a CSF-1R blocking antibody (Figure 9B). CSF-1R blockade inhibited CSF-1induced migration in MCF-7 cells by $45 \%$. We also show that IL-34 inhibited SK-BR-3 migration independent of the CSF-1R as shown in cells treated with the CSF$1 \mathrm{R}$ blocking antibody. This finding suggests that IL34 inhibits migration through the PTPRZ1 receptor, consistent with expression of PTPRZ1 and CSF-1R on SK-BR-3 cells. Furthermore, IL-34 increased migration of MDA-MB-231 cells in the presence of a blocking antibody against CSF-1R by $87 \%$, also suggesting a CSF$1 \mathrm{R}$-independent mechanism in this cell line (Figure 9B).

These findings demonstrate that IL-34 can promote or inhibit breast cancer cell migration depending on IL-34receptor expression profile and molecular subtype.

\section{Signal activation by IL-34 and CSF-1 exhibit differences in human breast cancer cells}

To clarify the signaling basis by which IL-34 and M-CSF may differently regulate breast cancer cells, we investigated signaling events triggered by IL-34 and CSF-1.

When analyzed by Western blotting, we found no obvious difference in the strength of CSF-1R, ERK, and FAK activation between IL-34- and CSF-1-stimulated MCF-7 breast cancer cells (Figure 9B). However, we found obvious differences in protein phosphorylation between IL-34- and CSF-1-stimulated SK-BR-3 and MDA-MB-231 cells (Figure 9C). It has been shown that CSF-1R rapidly phosphorylates its own tyrosine residues Tyr708 and Tyr723 when activated by IL-34, which triggers the interaction of the activated receptor with downstream signaling molecules [22]. IL-34 strongly phosphorylated tyrosine residue Tyr708 of the CSF$1 \mathrm{R}$ in SK-BR-3 cells, whereas Tyr708 phosphorylation remained unchanged by IL-34 in MDA-MB-231 cells. On the contrary, the Tyr708 signals declined rapidly in SK-BR-3 and MDA-MB-231 cells treated with CSF-1. Phosphorylation of tyrosine residue Tyr723 of the CSF-1R declined by IL-34 and CSF-1 in SK-BR-3 cells, while no Tyr723 phosphorylation was found in MDA-MB-231 and MCF-7 cells. We also observed differences in extracellular signal-regulated kinase (ERK) phosphorylation between cell lines (Figure 9C). We show that both CSF-1 and 1L-34 triggered ERK phosphorylation in MDA-MB-231
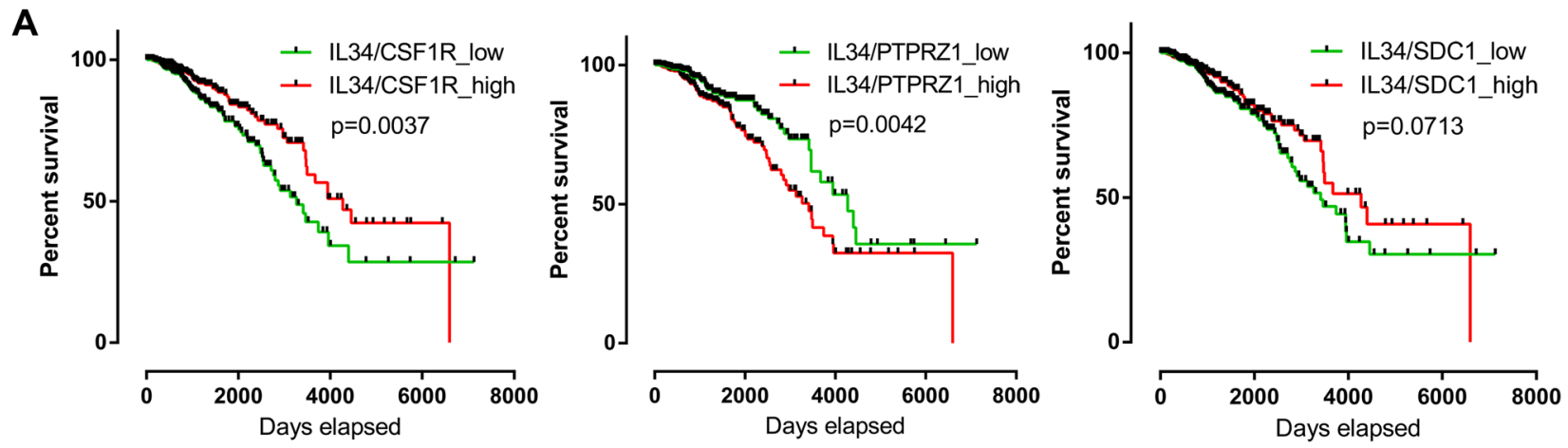

B
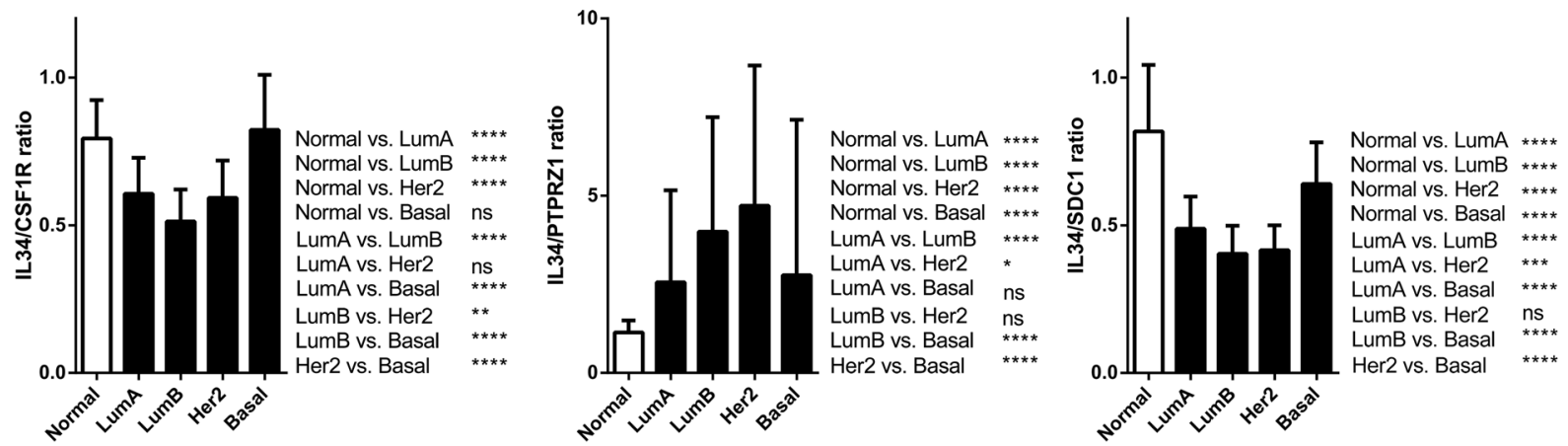

Figure 6: IL-34 ligand-receptor mRNA expression ratio. (A) Kaplan-Meier plots of overall survival between IL-34/CSF1R, IL34/PTPRZ1, and IL-34/SDC1 mRNA ratio high and low breast cancer patients $(n=1056)$ of the TCGA BRCA dataset. Median expression values were used as cut-offs for group separation. Log rank tests were calculated. (B) IL-34/CSF1R, IL-34/PTPRZ1, and IL-34/SDC1 mRNA ratio median values in normal breast tissue and in PAM50 breast cancer subclasses. The bar graph shows the IL-34/receptor mRNA ratio across normal breast tissue $(n=113)$ and the molecular subtypes of breast cancer (luminal A, $n=412$; luminal B, $n=188$; HER2enriched, $\mathrm{n}=64$; basal, $\mathrm{n}=140$ ) of the TCGA BRCA dataset. Kruskal-Wallis and Dunn's multiple comparison tests were calculated. Error bars indicate standard deviations. ${ }^{*}, p<0.05 ;{ }^{* *}, p<0.01 ;^{* * *}, p<0.001 ;{ }^{* * *}, p<0.0001$. 
cells, whereas a rapid and strong decline of ERK phosphorylation was observed in SK-BR-3 cells.

Phosphorylation of focal adhesion kinase (FAK) by IL-34 and CSF-1 has also been reported [34]. Importantly, a strong and rapid decline of focal adhesion kinase (FAK) phosphorylation at residue Tyr397 by CSF-1 but not IL34 was observed in MDA-MB-231 cells, whereas FAK phosphorylation increased by IL-34 and CSF-1 treatment in SK-BR-3 cells (Figure 9C).

Collectively, these results indicated that IL-34 and CSF-1 differentially activated signaling pathways in three breast cancer cell lines representing luminal, HER-2 and basal intrinsic subtypes.

\section{DISCUSSION}

IL-34 has received much attention as a newly discovered member of the interleukin family, which shares the CSF-1R with CSF-1 [12]. However, while the role of
CSF-1/CSF-1R has been extensively studied in breast cancer, the implication of IL-34 in breast cancer formation and progression is still poorly understood.

In this article, correlative analysis of IL-34 expression and breast cancer prognosis stratified by PAM50 tumor subtype showed an unexpected prognostic relationship between intrinsic subtype and overall survival that demonstrated patterns contrasting previous studies analyzing CSF-1 and CSF-1R. Specifically, high IL-34 levels were linked to better prognosis in luminal and HER2 subtypes, but to poorer prognosis in the basal subtype. The finding that high levels of IL-34 are associated with better prognosis in certain breast cancer subtypes is surprising, since the expression of CSF-1 and the common receptor CSF-1R has been linked to aggressive behavior and poor prognosis in breast cancer patients[29, 35-37]. CSF1 recruits macrophages to the tumor site on the one hand [37] and CSF-1-educated TAMs have a central role in supporting tumor cell survival, proliferation, motility and
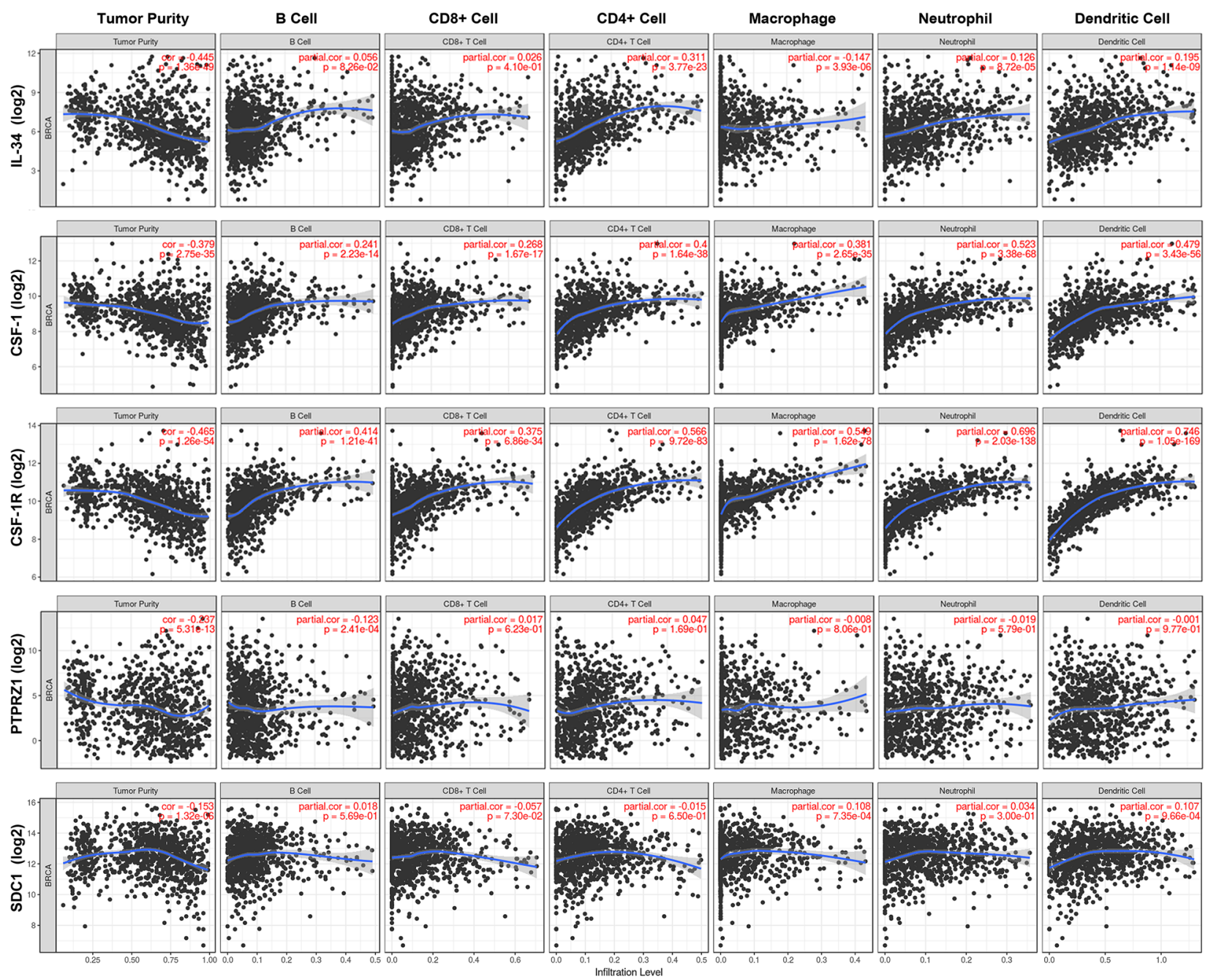

Figure 7: Immune cell landscape of breast cancer compared with TCGA gene expression of $I L-34, C S F-1, C S F-1 R$, PTPRZ1, and SDC1 (syndecan-1). Scatter plots were generated using the online tool TIMER to identify different profiles of immune cells associated with investigated genes. Each dot represents a single tumor sample. (see also Table 5, Supplementary Table 1). 
Table 4: Immune cell landscape compared with gene expression

\begin{tabular}{|c|c|c|c|c|c|c|c|}
\hline & $\begin{array}{c}\text { Tumor purity } \\
\text { r }\end{array}$ & $\begin{array}{c}\text { B cell } \\
\mathbf{r}\end{array}$ & $\begin{array}{c}\text { CD8+ } \mathrm{T} \text { cell } \\
\mathbf{r}\end{array}$ & $\begin{array}{c}\text { CD4+ } \mathrm{T} \text { cell } \\
\mathbf{r}\end{array}$ & $\begin{array}{c}\text { Macrophage } \\
\text { r }\end{array}$ & $\begin{array}{c}\text { Neutrophil } \\
\text { r }\end{array}$ & $\begin{array}{c}\text { Dendritic cell } \\
\text { r }\end{array}$ \\
\hline IL-34 & -- & & & ++ & - & + & + \\
\hline CSF-1 & -- & + & + & ++ & ++ & +++ & ++ \\
\hline CSF-1R & -- & ++ & ++ & +++ & +++ & +++ & +++ \\
\hline PTPRZ1 & - & - & & & & & \\
\hline SDC1 & - & & & & + & & + \\
\hline
\end{tabular}

Categorized Pearson's product-moment correlation of immune cell landscape of breast cancer compared with TCGA gene expression of IL-34, CSF-1, CSF-1R, PTPRZ1, and SDC1 (syndecan-1) (TIMER).

$\mathrm{r}$, categorized Pearson's correlation coefficient;

$(---),-1.0$ to -0.5 , strong negative association; $(--),-0.5$ to -0.3 , weak negative association; $(-),-0.3$ to 0.1 , little association. $(+),+0.1$ to 0.3 , little association; $(++)+0.3$ to +0.5 , weak positive association; $(+++),+0.5$ to +1.0 , strong positive association.

in suppressing anti-tumor immunity on the other [38]. Characterization of macrophage phenotypes in breast cancer subtypes using CIBERSORT_LM22 values and the TCIA database showed, as expected, that CSF-1/CSF-1R expression was positively associated with macrophages in all subtypes in the analyzed dataset.

Quite on the contrary, analysis of the immune cell landscape revealed even a slight negative correlation between IL-34 expression and macrophages. Broken down by molecular subtype and macrophage phenotypes revealed that high IL-34 expression correlated negatively with immunosuppressive M2 and positively with M1 polarized tumor suppressor macrophages in luminal subtypes, whereas no correlation with macrophages was found in HER2 and basal subtypes. These findings suggest that the functional role of IL-34 is not coupled to TAMs with an M2-like phenotype in breast cancer. However, it must be taken into account that IL-34 and CSF-1 were associated with different infiltrating immune cell subsets. Varying composition of the infiltrating immune cell subsets in turn may induce a diversity of TAM subtypes, different to the conventional M1/M2 phenotypes [39]. Likewise, as a result of tumor cell heterogeneity distinct populations of TAMs with different phenotypes and functions can be found in the same tumor [40].

Additionally, cancer cells may consume IL-34 in certain subtypes at the same time, since CSF-1/CSF-1R but not IL-34 were strongly associated with stromaland immune-score in HER2 and basal subtypes. In this regard, the observed differences in the IL-34/CSF-1R ratio may play a role in both, myeloid and cancer cells. In vitro experiments in luminal and basal type breast cancer cells revealed that IL-34 and CSF-1 differentially regulate cancer cell migration dependent on the molecular subtype. IL-34 promoted cancer cell migration in basal MDA-MB-231 breast cancer cells independent of the CSF-1R, while it reduced cancer cell migration in HER2- positive SK-BR-3 cells. In contrast, IL-34 had no effect on luminal MCF-7 cancer cell migration, which was regulated by CSF-1/CSF-1R. These findings are in favor of the hypothesis that cancer cells are directly affected by IL-34 signaling via alternative IL-34 receptors.

Consequently, the biology of IL-34 is complex and other reports also suggest that its actions are not expected to be identical to CSF-1/CSF-1R signaling [34, 41]. IL-34 shares very little homology with CSF-1 and has a higher affinity to the CSF-1R $[12,42]$. Even more important, binding of IL-34 to PTPRZ1 [21] and syndecan-1 [22] through low affinity interactions with chondroitin sulphate chains demonstrates that the CSF-1R is not mediating all the actions of IL-34.

PTPRZ1 is a member of the receptor tyrosine phosphatase family [21, 43, 44]. Activation of PTPZ leads to increased tyrosine phosphorylation of several transduction pathways and is upregulated in many human cancers, such as lung and prostate cancers, and regulates their proliferation and metastasis [15]. Noteworthy, IL34 selectively bound PTPRZ1 in CSF-1R-deficient U251 human glioblastoma cells and led to an increase in the tyrosine phosphorylation of FAK and suppression of cell motility [21]. Fittingly, in HER2-positive SK-BR-3 cells IL-34 stimulation increased FAK phosphorylation and decreased cell migration. On the other hand, in basal MDA-MB-231 cells, IL-34 decreased FAK phosphorylation and increased cell migration independent of the CSF-1R. Moreover, only little (luminal A) or no correlation was found for PRTPRZ1 expression with stromal and ESTIMATE scores and also no positive correlation with the immune score, which is consistent with an additional action of IL-34 via the PRTPRZ1 on cancer cells. Together with our in vitro experiments these findings suggest that CSF-1R-independent actions of IL34 via PTPRZ1 should be considered in evaluating IL-34 roles in breast cancer subtypes. 
Table 5: Macrophage infiltration scores and stromal score compared with gene expression

\begin{tabular}{lccccc} 
& Monocytes & M0 & M1 & M2 & Stromal sc \\
& r & r & r & r & r \\
\hline IL-34 & & & ++ & -- & + \\
CSF-1 & + & & + & + \\
CSF-1R & & & + & - & ++ \\
PTPRZ1 & & & & + \\
SDC1 & & + & & + \\
\hline
\end{tabular}

Categorized Pearson's product-moment correlation correlation between IL-34, CSF-1, CSF-1R, PTPRZ1 and SDC1 (syndecan-1) mRNA expression and M0, M1, M2 and monocyte infiltration scores (obtained from TCIA database) in tumor samples from the TCGA BRCA dataset. M0, M0 macrophages; M1, M1 macrophages; M2, M2 macrophages; Stromal sc, Stromal score; r, categorized Pearson's correlation coefficient;

$(---),-1.0$ to -0.5 , strong negative association; $(--),-0.5$ to -0.3 , weak negative association; $(-),-0.3$ to 0.1 , little association. $(+),+0.1$ to 0.3 , little association; $(++)+0.3$ to +0.5 , weak positive association; $(+++),+0.5$ to +1.0 , strong positive association.

Unlike PTPRZ1, syndecan-1 correlated with stromal score in all subtypes with the exception of basal subtype. Interestingly, a recent report showed that stromal syndecan-1 expression was associated with positive ER status, whereas epithelial syndecan-1 expression was associated with negative ER status [45]. However, reports on stromal syndecan-1 expression and prognosis in breast cancer are controversial $[27,45,46]$ and studies from an in vitro breast cancer model have suggested that syndecan-1 even directly participates in tumor cell spreading and adhesion[47]. Another report showed that IL-34 also induced the migration of myeloid cells in a syndecan-1dependent manner [22]. To complicate matters further, we found differential IL-34/syncdecan-1 ratios in molecular subtypes. This is important because the level of syndecan-1 has been suggested to regulate the interaction between IL34 and the CSF-1R [22]. Importantly, syndecan-1 was not or only weakly associated with macrophages and immune score in our analysis. A link to M0 and M2 macrophages in the HER2 subtype was the only noticeable link observed. Moreover, analysis of macrophage phenotypes showed that the correlation patterns of IL-34 and syndecan-1 were quite different in all molecular subtypes. Thus, we assume that syndecan-1 and IL-34 do not act in concert to regulate macrophages in breast cancer.

Calculation of the ESTIMATE score, to infer tumor purity, and of the stromal score revealed that CSF-1 and CSF-1R are strongly linked to the stromal compartment in all subtypes. In contrast, association of IL-34 with stromal score was confined to luminal subtypes, while PTPRZ1 was not associated with this score in any subtype. Together with the observed low CSF-1R activation in breast cancer cells, we hypothesize that IL-34 and its receptor PTPRZ1 directly regulate cancer cells, whereas CSF-1/CSF-1R are primarily involved in regulation of stromal and immune cells.
In support of this, we observed considerable differences in the composition of the immune infiltrate between breast cancer subtypes by comparing immune cell infiltration with gene expression using the online tool TIMER. CSF-1/CSF-1R were strongly associated with myeloid cell (macrophages, neutrophils, dendritic cells) infiltration. This contrasts sharply with the weak or absent correlation between tumor-infiltrating myeloid cells and expression of IL-34, PTPRZ1, and syndecan-1. An interesting observation in this context is that higher levels of tumor-infiltrating myeloid cells contribute to increased malignancy and correlate with poorer survival $[48,49]$. Strikingly, the CSF-1R is not only expressed by macrophages, but also by dendritic cells (DCs), in Langerhans cells, B cells, and to some extent granulocytes including neutrophils (see [15] and references therein). Moreover, neutrophils can produce large amounts of CSF-1 [50]. In contrast to CSF-1, IL34 is not expressed by myeloid cells and, consequently, has no autocrine role in this context [39], providing further support for a differential role of CSF-1 and IL34 in myeloid cells. Gentles et al. previously reported neutrophils to be prognostic in breast cancer [49] and a larger proportion of neutrophils was associated with poor outcome in ER+/HER2+ and ER-negative tumors [48]. Recently, neutrophils were shown to promote metastasis through immunosuppression in a model of breast cancer [51]. Importantly, growing evidence also shows that the breast cancer tumor microenvironment can change the phenotype of dendritic cells, transforming them into immunosuppressive DCs, which limit the activity of effector $\mathrm{T}$ cells and supports tumor growth and progression [52, 53]. A recent analysis of immune cell subsets in breast cancer has found that activated dendritic cells were strongly associated with poor outcome in ER+/HER2+ tumors [48]. Furthermore, CSF-1/CSF-1R 
also showed a higher correlation with tumor infiltrating lymphocytes (TILs) than IL-34, PTPRZ1, and syndecan-1. High numbers of TILs can be found in triple negative and HER2-positive tumors [54]. Together, these findings could, at least partly, explain the observed favorable outcome associated with IL-34.
In conclusion, our study shows that the mRNA expression pattern of IL-34 was distinct from CSF-1 and associated with a favorable prognosis dependent on the molecular breast cancer subtype. In addition, gene expression patterns of CSF-1 and CSF-1R but not IL34 were associated with myeloid cell infiltration. These
A

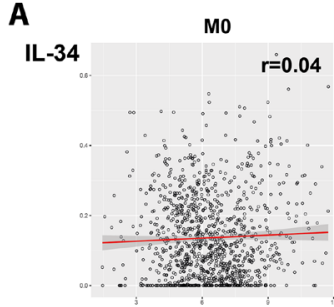

CSF-1

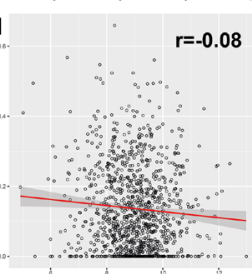

CSF-1R

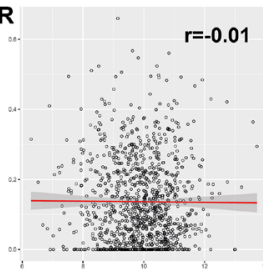

$r=-0.01$

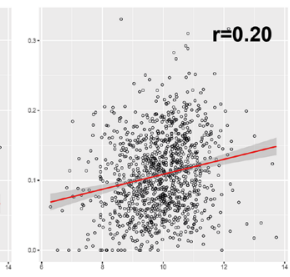

PTPRZ1

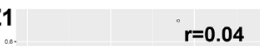

$r=0.04$

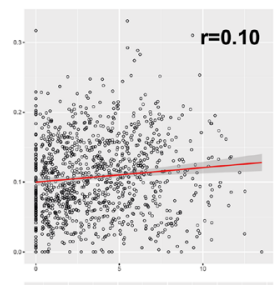

SDC1
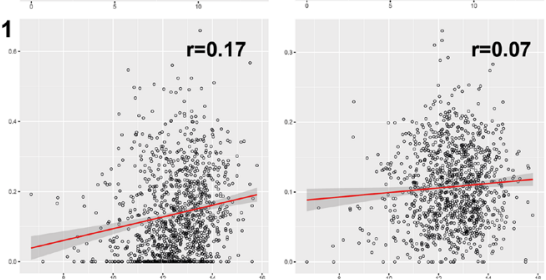

B

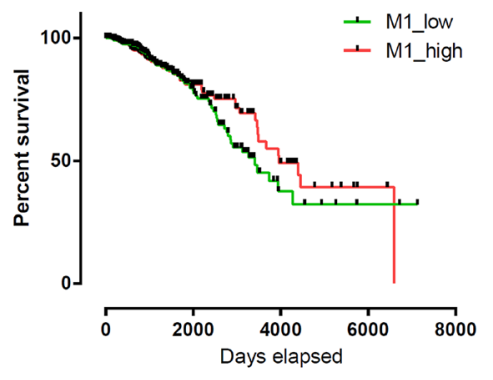

M2
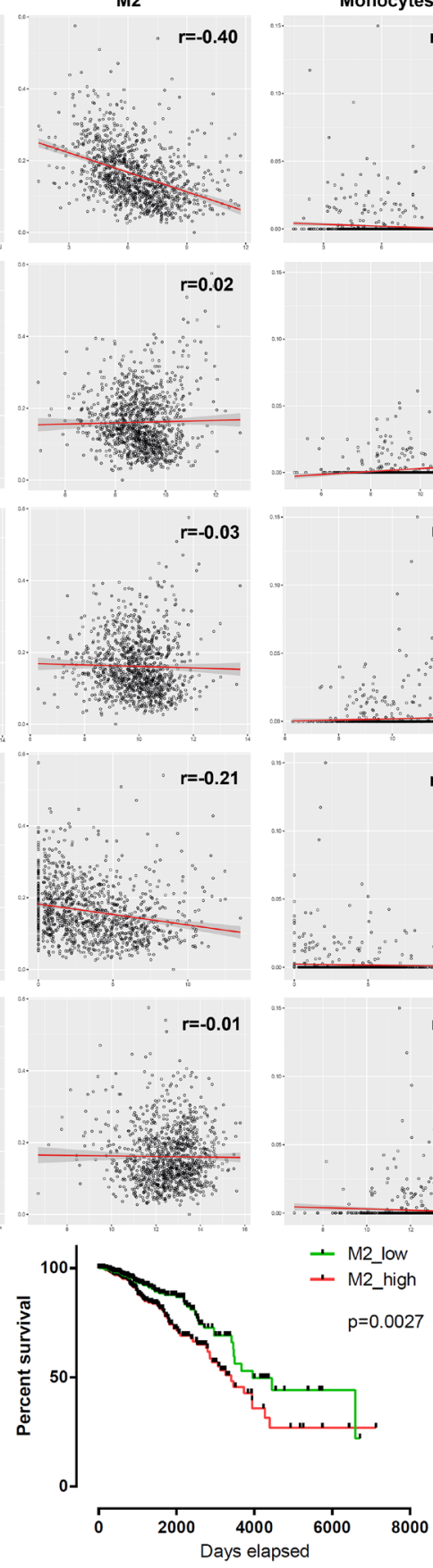
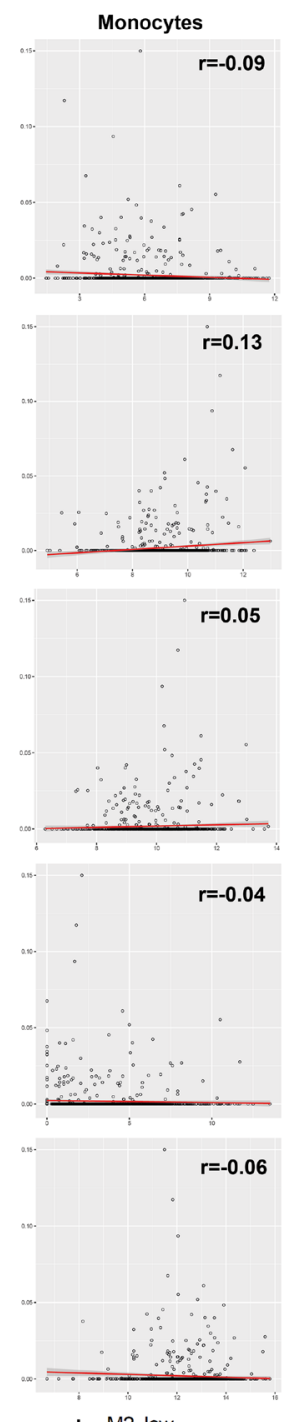

$-0.06$

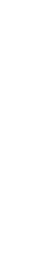


Table 6: Macrophage infiltration and stromal cell/immune cell infiltration in breast tumors stratified by PAM50 calls Luminal A subtype - Categorized Pearson's product-moment correlation

\begin{tabular}{|c|c|c|c|c|c|c|}
\hline & $\begin{array}{c}\text { M0 } \\
\mathrm{r}\end{array}$ & $\begin{array}{c}\text { M1 } \\
\mathrm{r}\end{array}$ & $\begin{array}{c}\text { M2 } \\
\mathrm{r}\end{array}$ & $\begin{array}{c}\text { Stromal sc } \\
\mathrm{r}\end{array}$ & $\begin{array}{c}\text { Immune sc } \\
\mathrm{r}\end{array}$ & $\begin{array}{c}\text { ESTIMATE sc } \\
\mathrm{r}\end{array}$ \\
\hline IL-34 & - & ++ & --- & ++ & ++ & +++ \\
\hline CSF-1 & & & + & ++ & ++ & ++ \\
\hline CSF-1R & & + & & +++ & +++ & +++ \\
\hline PTPRZ1 & - & + & -- & + & & + \\
\hline SDC1 & + & & & +++ & & ++ \\
\hline
\end{tabular}

Luminal B subtype - Categorized Pearson's product-moment correlation

\begin{tabular}{|c|c|c|c|c|c|c|}
\hline & $\begin{array}{c}\text { M0 } \\
\mathrm{r}\end{array}$ & $\begin{array}{c}\text { M1 } \\
\text { r }\end{array}$ & $\begin{array}{c}\text { M2 } \\
\mathrm{r}\end{array}$ & $\begin{array}{c}\text { Stromal sc } \\
\mathrm{r}\end{array}$ & $\begin{array}{c}\text { Immune sc } \\
\mathrm{r}\end{array}$ & $\begin{array}{c}\text { ESTIMATE Sc } \\
\mathrm{r}\end{array}$ \\
\hline IL-34 & & ++ & -- & ++ & ++ & ++ \\
\hline CSF-1 & & & + & ++ & +++ & +++ \\
\hline CSF-1R & & + & & +++ & +++ & +++ \\
\hline \multicolumn{7}{|l|}{ PTPRZ1 } \\
\hline SDC1 & & + & & ++ & + & ++ \\
\hline
\end{tabular}

HER2 subtype -Categorized Pearson's product-moment correlation

\begin{tabular}{|c|c|c|c|c|c|c|}
\hline & $\begin{array}{c}\text { M0 } \\
\text { r }\end{array}$ & $\begin{array}{c}\text { M1 } \\
\text { r }\end{array}$ & $\begin{array}{c}\text { M2 } \\
\mathrm{r}\end{array}$ & $\begin{array}{c}\text { Stromal sc } \\
\mathrm{r}\end{array}$ & $\begin{array}{c}\text { Immune sc } \\
\mathrm{r}\end{array}$ & $\begin{array}{c}\text { ESTIMATE sc } \\
\mathrm{r}\end{array}$ \\
\hline IL-34 & & & -- & & ++ & ++ \\
\hline CSF-1 & & & & +++ & +++ & +++ \\
\hline CSF-1R & & & & +++ & +++ & +++ \\
\hline \multicolumn{7}{|l|}{ PTPRZ1 } \\
\hline SDC1 & ++ & - & ++ & ++ & & \\
\hline
\end{tabular}

Basal subtype -Categorized Pearson's product-moment correlation

\begin{tabular}{|c|c|c|c|c|c|c|}
\hline & $\begin{array}{c}\text { M0 } \\
\mathrm{r}\end{array}$ & $\begin{array}{c}\text { M1 } \\
\mathrm{r}\end{array}$ & $\begin{array}{c}\text { M2 } \\
\mathrm{r}\end{array}$ & $\begin{array}{c}\text { Stromal sc } \\
\mathrm{r}\end{array}$ & $\begin{array}{c}\text { Immune sc } \\
\mathrm{r}\end{array}$ & $\begin{array}{c}\text { ESTIMATE sc } \\
\mathrm{r}\end{array}$ \\
\hline IL-34 & & & & + & + & + \\
\hline CSF-1 & & ++ & - & +++ & +++ & +++ \\
\hline CSF-1R & & ++ & & +++ & +++ & +++ \\
\hline PTPRZ1 & + & - & & & - & \\
\hline SDC1 & & & & & & \\
\hline
\end{tabular}

Association between mRNA expression of 5 genes and macrophage infiltration as well as stromal cell/immune cell infiltration in breast tumors stratified by PAM50 calls from the TCGA BRCA dataset.

M0, M0 macrophages; M1, M1 macrophages; M2, M2 macrophages; Stromal sc, Stromal score; Immune sc, Immune score; Estimate sc, Estimate score. r, categorized Pearson's correlation coefficient;

$(---),-1.0$ to -0.5 , strong negative association; $(--),-0.5$ to -0.3 , weak negative association; $(-),-0.3$ to 0.1 , little association. $(+),+0.1$ to 0.3 , little association; $(++)+0.3$ to +0.5 , weak positive association; $(+++),+0.5$ to +1.0 , strong positive association. M0, M1, M2 (TCIA database); Stromal sc., Immune sc., Estimate sc. (ESTIMATE database). 


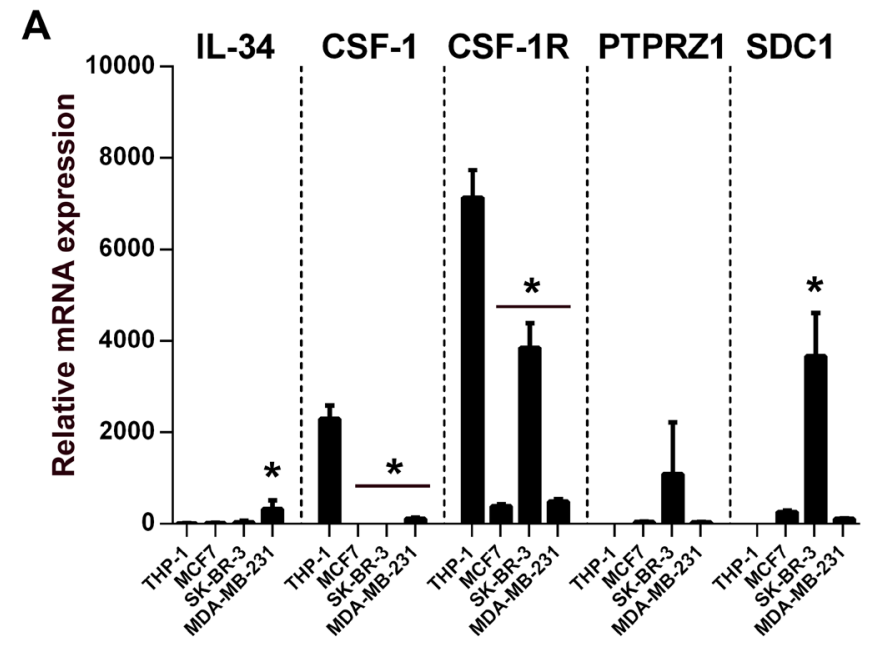

B

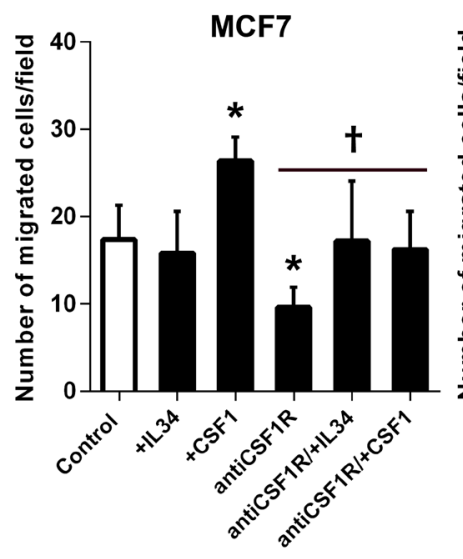

C

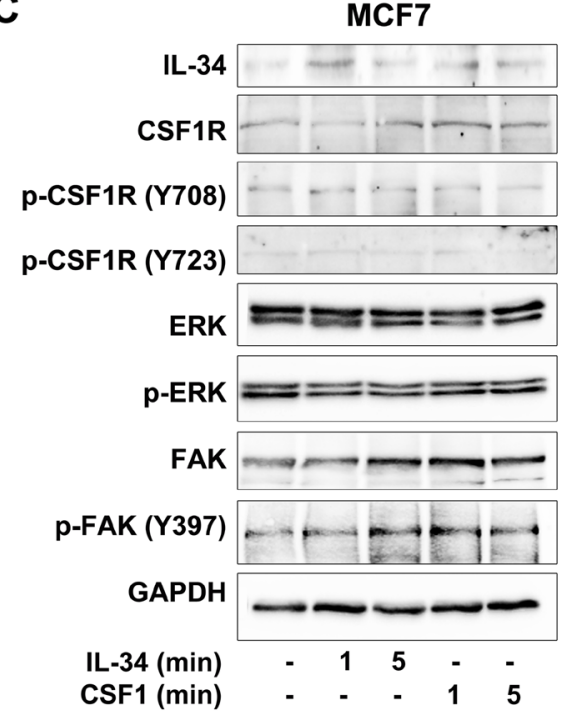

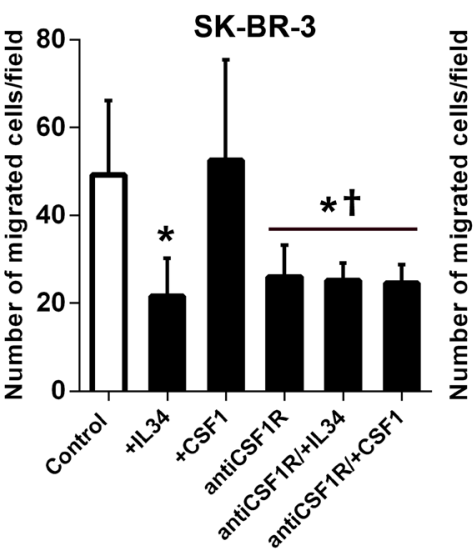

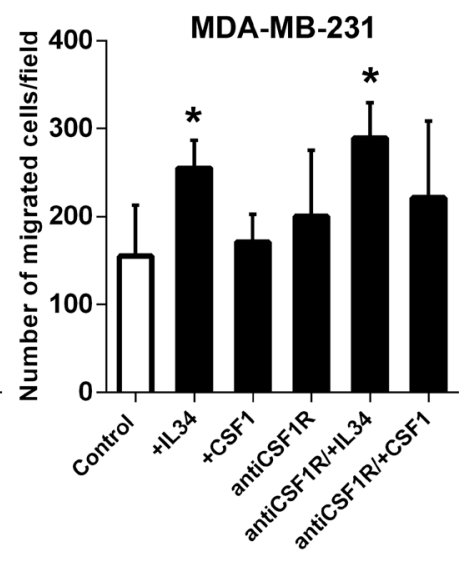

SK-BR-3
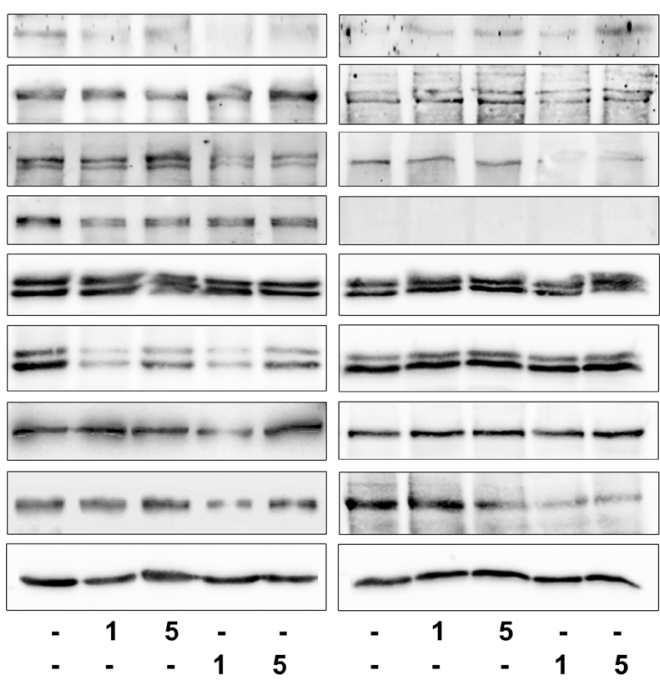

$35 \mathrm{kDa}$

$\sim 180 \mathrm{kDa}$

$\sim 180 \mathrm{kDa}$

$\sim 180 \mathrm{kDa}$

44/42 kDa

44/42 kDa

125 kDa

$125 \mathrm{kDa}$

$37 \mathrm{kDa}$

Figure 9: IL-34 differentially regulates migration and signaling of human breast cancer cell lines. (A) Comparison of gene expression in MCF7, SK-BR-3, and MDA-MB-231 breast cancer cells with THP-1 macrophages. Graphs show results of qRT-PCR for $I L-$ 34, CSF-1, CSF-1R, PTPRZ1 and SDC1 performed on RNA from human MCF7, SK-BR-3 and MDA-MB-231 breast cancer cells as well as THP-1 macrophages. (B) Quantification of migrated MCF7, SK-BR-3 and MDA-MB-231 breast cancer cells from an in vitro migration assay are shown. Cells were either left unstimulated (control) or stimulated with IL-34, CSF-1 or pretreated with CSF1-R blocking antibody (antiCSF1R) prior to cytokine treatment. ${ }^{*}, p<0.05$ vs. control;,$p<0.05$ vs recCSF1. (C) Differential regulation of signaling upon IL34 or CSF-1 treatment in human breast cancer cell lines. MCF7, SK-BR-3, and MDA-MB-231 breast cancer cells were stimulated with recombinant IL-34 or CSF-1 protein for the indicated times. Western blot images of indicated proteins in breast cancer cells are shown. p- indicates phosphorylated proteins. 
findings suggest different functions of IL-34 and CSF-1 in breast cancer.

\section{MATERIALS AND METHODS}

\section{Cell lines}

Our own data set of breast cancer cell lines included 14 cell lines derived from carcinomas: AU565, BT-474, CAL-51, CAMA-1, HCC1143, HCC1937, Hs 578T, MCF7, MDA-MB-231, MDA-MB-453, MDA-MB-468, SK-BR-3, T-47D, ZR-75-1. HMEC and Hs 578Bst represent normal mammary tissue, while MCF $10 \mathrm{~A}$ and MCF 10F were derived from a fibrocystic disease. All cell lines except HMEC were purchased from American Type Culture Collection (ATCC, Manassas, VA, USA) or "Deutsche Sammlung von Mikroorganismen und Zellkulturen" (DSMZ), and were cultivated at $37^{\circ} \mathrm{C}, 5 \%$ $\mathrm{CO}_{2}$, and $100 \%$ humidity. Finite-lifespan untransformed human mammary epithelial cells (HMEC) were kindly provided by M. R. Stampfer [55] and grown in MEGM medium. The human monocytic leukemia cell line THP-1 was cultured in RPMI1640 (Lonza, Basel, Switzerland) medium supplemented with 10\% FBS (Life Technologies, Carlsbad, CA, USA) and 2-mercaptoethanol (SigmaAldrich, St. Louis, MO, USA) to a final concentration of $0.05 \mathrm{mM}$. For differentiation of THP-1 cells into mature macrophages, THP-1 cells were cultured in growth medium with $150 \mathrm{nM}$ phorbol 12-myristate 13-acetate (PMA) (Sigma-Aldrich) for 48 h [56].

\section{Study population}

Our own data set of clinical samples included 75 breast cancer cases of Caucasian background from a study population described in detail in [57]. The study was approved by the institutional review board of the Medical University of Vienna (MUV), Vienna, Austria. For those patients who had undergone surgery before the onset of the study, a waiver of specific informed consent was approved by the IRB.

\section{Quantitative real-time RT-PCR (qRT-PCR)}

Isolation of total RNA with TRIreagent (Sigma), quality control with the Bioanalyser 2100 (Agilent, Santa Clara, CA, USA), and reverse transcription with the high-capacity cDNA archive Kit (Applied Biosystems, Foster City, CA, USA) have been described [57]. Each sample was analyzed in duplicate by quantitative reverse transcription-PCR (qRT-PCR) on an Applied Biosystems 7500 fast real-time PCR instrument, using gene-specific primers and fluorescent probes obtained from Applied Biosystems: IL-34, Hs01050926; $\beta$-actin, Hs99999903. The mRNA levels of IL-34 were normalized to those of $\beta$-actin in each sample. All relative IL-34 mRNA expression levels are presented as $\log 2$ values.

For in vitro assays, MCF7, SK-BR-3 and MDA-MB-231 breast cancer cells were processed for PCR as described [58]. The primer sequences for analyzed factors are as follows (sense/antisense): IL34: 5'-AATCCGTGTTGTCCCTCTTG-3'/5'-CAGTA CAGCAGCTCCATGACC-3'; CSF-1: 5'-GCTGTTGTT GGTCTGTCTC-3'/5'-CATGCTCTTCATAATCCTTG-3'; CSF-1R: 5'-CTGAGCAAGACCTGGACAAGG-3'/5'-TG CTGTTCACCAGGATGCCAG-3'; PTPRZ1: 5'-TCTA CTGCTTTGATGCGGACC-3'/5'-ACGACTAACACTTT CGACTCC-3'; SDC1: 5'- GGGACTCAGCCTTCAGA CAG-3'/5'-CTCGTCAATTTCCAGGAGGA-3'. LCDA Version 3.5.3 (Roche, Mannheim, Germany) was used for PCR data analysis. Relative quantification of the signals was performed by normalizing the signals of the different genes to $\beta 2$-microglobulin as described [58].

\section{Migration assay}

MCF7, SK-BR-3 and MDA-MB-231 breast cancer cell lines were starved over night in serum-free DMEM medium. Breast cancer cells $\left(1 \times 10^{5}\right)$ in DMEM with $2 \%$ FBS were added to the top of each Boyden migration chamber $(8 \mu \mathrm{m}, 12$-well plate format; BD Biosciences, Palo Alto, CA) with or without CSF-1R-blocking antibody $(10 \mu \mathrm{g} / \mathrm{ml})$ followed by treatment with $200 \mathrm{ng} /$ $\mathrm{ml}$ recombinant IL-34 or CSF-1 protein (R\&D Systems, McKinley Place, MN, USA). After 48 h, medium was removed and membranes were processed as described [59].

\section{Protein isolation and Western blotting}

Breast cancer cell lines were starved for $24 \mathrm{~h}$, one portion of cells was left untreated and one portion of cells was incubated with $200 \mathrm{ng} / \mathrm{ml}$ recombinant IL-34 or CSF1 protein for 1 or $5 \mathrm{~min}$. Cell lysates were prepared as described [60] and $25 \mu \mathrm{g} / \mathrm{lane}$ were separated by $8 / 14 \%$ SDS-PAGE prior to electrophoretic transfer onto Amersham Protan Supported $0.2 \mu \mathrm{m}$ Nitrocellulose membrane (GE Healthcare, Buckinghamshire, UK). The blots were probed with antibodies against IL-34 (Thermo Fisher Scientific, Waltham, MA, USA), CSF-1R (R\&D Systems, McKinley Place, MN, USA), phospho-CSF-1R(Tyr708), phospho-CSF-1R(Tyr723), ERK1/2, phospho-44/42 ERK1/2(Thr202/Tyr204), FAK and pFAK(Tyr397) (Cell Signaling Technology, Danvers, MA, USA) before incubation with horseradish peroxidase-conjugated secondary antibodies (GE Healthcare). GAPDH-HRP staining (Sigma) was used as loading control. Proteins were immunodetected by chemiluminescence (Ace Glow, Peqlab, Erlangen, Germany), scanned using FUSION-FX7 (Vilber Lourmat, Marne-la-Vallée, France) and quantified by Fusion-CAPT-Software 16.07 (Vilber Lourmat). 


\section{Publically available datasets}

Level 3 normalized IlluminaHiSeq RNAsequencing (RNA-seq) data and clinical data from the "The Cancer Genome Atlas" (TCGA) BRCA (breast cancer) dataset were obtained from the Cancer Browser database (https://genome-cancer.ucsc.edu). mRNA expression values of the genes $I L-34, C S F-1, C S F-1 R$, PTZRZ1 and SDC1 were extracted from the expression matrix. Overall, mRNA expression data of 1102 breast cancer samples and 113 normal breast tissue samples were available. Information regarding OS was available for 1056 patients. PAM50 calls (luminal A, luminal B, HER2, basal-like and normal-like) were available for 826 patients. Because of the low number, normal-like tumors were excluded from analyses.

\section{Correlation of mRNA expression and immune cell infiltration}

mRNA expression data of $I L-34, C S F-1, C S F-$ $1 R, P T Z R Z 1$ and SDC1 in TCGA BRCA tumor samples were correlated with tumor infiltration of 6 immune cell types (B cells, CD4+ T cells, CD8+ T cells, neutrophils, macrophages and dendritic cells) using the online tool TIMER (Tumor IMmune Estimation Resource; https:// cistrome.shinyapps.io/timer/; [61, 62]). In addition, information about tumor purity was obtained from TIMER.

For a more detailed analysis regarding macrophage infiltration and mRNA expression of the 5 genes in the TCGA BRCA dataset, CIBERSORT_LM22 values for monocytes and M0, M1 and M2 macrophages were obtained from "The Cancer Immunome Database" (TCIA, https://tcia.at/home, [32]). These values were then merged with RNA-seq data of the tumor samples. Overall, TCIA scores and RNA-seq data were available for 1091 breast cancer samples.

\section{ESTIMATE scores (Tumor Purity, Stromal score, Immune score)}

ESTIMATE (Estimation of STromal and Immune cells in MAlignant Tumor tissues using Expression data) was used as a resource to get information about tumor purity (proportion of cancer cells in the tumor), and the presence of infiltrating stromal and immune cells in breast cancer tissues from TCGA BRCA gene expression data [63]. This algorithm is based on single sample Gene Set Enrichment Analysis and generates three scores: a stromal score (that captures the presence of stroma in tumor tissue), an immune score (that represents the infiltration of immune cells in tumor tissue), and the ESTIMATE score (that infers tumor purity). ESTIMATE scores for 1100 TCGA BRCA samples were obtained from http://bioinformatics.mdanderson.org/estimate/ and merged with RNA-seq data. Overall, ESTIMATE data and RNA-seq data were available for 1091 breast cancer samples.

\section{Statistical analysis}

Statistical analyses were performed with Statistical Package for the Social Sciences (SPSS) software (version 22.0, SPSS Inc., Chicago, IL, USA) and R version 2.15.1 ("Roasted Marshmallows"), an open-source language and environment for statistical computing [32]. Differences between the indicated groups with respect to relative IL34 mRNA levels were analyzed by unpaired, two-sided $t$-tests or one-way analysis of variance (ANOVA) with post hoc tests. Kaplan-Meier survival curves were used to estimate OS, DFS, and MFS and the survival differences between high-expression and low-expression groups were assessed by log-rank tests as described [64]. All results were considered statistically significant when $p$ values were less than 0.05 . All statistical tests were two-sided.

Statistical analyses of TCGA data were performed using R version 3.2.1 and GraphPad Prism 6 software (GraphPad Software Inc., La Jolla, CA, USA). Data normality was tested using the Shapiro-Wilk test. Differences between 2 groups were calculated by unpaired, two-sided Mann-Whitney $U$ tests and differences between $>2$ groups were calculated by Kruskal-Wallis and Dunn's multiple comparison tests. Survival curves were plotted using the Kaplan-Meier method and compared using log-rank test. Correlation analyses were performed using the cortest function of $\mathrm{R}$ and visualized using the ggplot 2 package. All results were considered statistically significant when $p$ values were less than 0.05 . All statistical tests were two-sided.

\section{Author contributions}

$\mathrm{KZ}$, DA were responsible for the experimental design of the study. KZ, MM, MS, and DA performed the experiments and drafted the manuscript. GH, MS, and KZ collected the data. KZ, GH, MS and DA participated in the data analysis and interpretation. Final manuscript was read and approved by all authors.

\section{ACKNOWLEDGMENTS}

We thank Sandra Trojanek and Andrea Friesenhengst for technical assistance.

\section{CONFLICTS OF INTEREST}

GH received research funding from Bristol-Myers Squibb. All other authors have nothing to declare.

\section{FUNDING}

This work was supported by the Herzfelder'sche Familienstiftung. 


\section{REFERENCES}

1. Torre LA, Bray F, Siegel RL, Ferlay J, Lortet-Tieulent J, Jemal A. Global cancer statistics, 2012. CA Cancer J Clin. 2015; 65:87-108. https://doi.org/10.3322/caac.21262.

2. Place AE, Huh SJ, Polyak K. The microenvironment in breast cancer progression: Biology and implications for treatment. Breast Cancer Res. 2011; 13:227.

3. Kroemer G, Senovilla L, Galluzzi L, Andre F, Zitvogel L. Natural and therapy-induced immunosurveillance in breast cancer. Nat Med. 2015; 21:1128-38. https://doi. org/10.1038/nm.3944.

4. Williams CB, Yeh ES, Soloff AC. Tumor-associated macrophages: unwitting accomplices in breast cancer malignancy. NPJ Breast Cancer. 2016; 2:15025. https://doi. org/10.1038/npjbcancer.2015.25.

5. Hanahan D, Weinberg RA. Hallmarks of cancer: the next generation. Cell. 2011; 144:646-74. https://doi. org/10.1016/j.cell.2011.02.013.

6. Chitu V, Stanley ER. Colony-stimulating factor-1 in immunity and inflammation. Curr Opin Immunol. 2006; 18:39-48. https://doi.org/10.1016/j.coi.2005.11.006.

7. Roth P, Stanley ER. The biology of CSF-1 and its receptor. Curr Top Microbiol Immunol. 1992; 181:141-67. https:// doi.org/10.1007/978-3-642-77377-8_5.

8. Aharinejad S, Paulus P, Sioud M, Hofmann M, Zins K, Schäfer R, Stanley ER, Abraham D. Colony-stimulating factor-1 blockade by antisense oligonucleotides and small interfering RNAs suppresses growth of human mammary tumor xenografts in mice. Cancer Res. 2004; 64:5378-84. https://doi.org/10.1158/0008-5472.CAN-04-0961.

9. Paulus P, Stanley ER, Schäfer R, Abraham D, Aharinejad S. Colony-stimulating factor-1 antibody reverses chemoresistance in human $\mathrm{MCF}-7$ breast cancer xenografts. Cancer Res. 2006; 66:4349-56. https://doi. org/10.1158/0008-5472.CAN-05-3523.

10. Aharinejad S, Salama M, Paulus P, Zins K, Berger A, Singer CF. Elevated CSF1 serum concentration predicts poor overall survival in women with early breast cancer. Endocr Relat Cancer. 2013; 20:777-83.

11. MacDonald KP, Palmer JS, Cronau S, Seppanen E, Olver S, Raffelt NC, Kuns R, Pettit AR, Clouston A, Wainwright B, Branstetter D, Smith J, Paxton RJ, et al. An antibody against the colony-stimulating factor 1 receptor depletes the resident subset of monocytes and tissue- and tumorassociated macrophages but does not inhibit inflammation. Blood. 2010; 116:3955-63. https://doi.org/10.1182/ blood-2010-02-266296.

12. Lin H, Lee E, Hestir K, Leo C, Huang M, Bosch E, Halenbeck R, Wu G, Zhou A, Behrens D, Hollenbaugh D, Linnemann T, Qin M, et al. Discovery of a cytokine and its receptor by functional screening of the extracellular proteome. Science. 2008; 320:807-11. https://doi. org/10.1126/science.1154370.

13. Pixley FJ, Stanley ER. CSF-1 regulation of the wandering macrophage: complexity in action. Trends Cell Biol. 2004; 14: 628-38.

14. Foucher ED, Blanchard S, Preisser L, Garo E, Ifrah N, Guardiola P, Delneste Y, Jeannin P. IL-34 induces the differentiation of human monocytes into immunosuppressive macrophages. antagonistic effects of GM-CSF and IFN $\gamma$. PLoS One. 2013; 8:e56045. https://doi. org/10.1371/journal.pone.0056045.

15. Guillonneau C, Bézie S, Anegon I. Immunoregulatory properties of the cytokine IL-34. Cell Mol Life Sci. 2017; 74:2569-86. https://doi.org/10.1007/s00018-017-2482-4.

16. Baud'huin M, Renault R, Charrier C, Riet A, Moreau A, Brion R, Gouin F, Duplomb L, Heymann D. Interleukin-34 is expressed by giant cell tumours of bone and plays a key role in RANKL-induced osteoclastogenesis. J Pathol. 2010; 221:77-86. https://doi.org/10.1002/path.2684.

17. Segaliny AI, Mohamadi A, Dizier B, Lokajczyk A, Brion R, Lanel R, Amiaud J, Charrier C, Boisson-Vidal C, Heymann D. Interleukin-34 promotes tumor progression and metastatic process in osteosarcoma through induction of angiogenesis and macrophage recruitment. Int J Cancer. 2014; 4:29376.

18. Baghdadi M, Wada H, Nakanishi S, Abe H, Han N, Putra WE, Endo D, Watari H, Sakuragi N, Hida Y, Kaga K, Miyagi Y, Yokose T, et al. Chemotherapy-induced IL34 enhances immunosuppression by tumor-associated macrophages and mediates survival of chemoresistant lung cancer cells. Cancer research. 2016; 76:6030-42.

19. DeNardo DG, Brennan DJ, Rexhepaj E, Ruffell B, Shiao SL, Madden SF, Gallagher WM, Wadhwani N, Keil SD, Junaid SA, Rugo HS, Hwang ES, Jirström K, et al. Leukocyte complexity predicts breast cancer survival and functionally regulates response to chemotherapy. Cancer Discov. 2011; 1:54-67. https://doi.org/10.1158/2159-8274. CD-10-0028.

20. Zhou SL, Hu ZQ, Zhou ZJ, Dai Z, Wang Z, Cao Y, Fan J, Huang XW, Zhou J. miR-28-5p-IL-34-macrophage feedback loop modulates hepatocellular carcinoma metastasis. Hepatology. 2016; 63:1560-75. https://doi. org/10.1002/hep. 28445 .

21. Nandi S, Cioce M, Yeung YG, Nieves E, Tesfa L, Lin H, Hsu AW, Halenbeck R, Cheng HY, Gokhan S, Mehler MF, Stanley ER. Receptor-type protein-tyrosine phosphatase $\zeta$ is a functional receptor for interleukin-34. J Biol Chem. 2013; 288:21972-86. https://doi.org/10.1074/jbc.M112.442731.

22. Segaliny AI, Brion R, Mortier E, Maillasson M, Cherel M, Jacques Y, Le Goff B, Heymann D. Syndecan-1 regulates the biological activities of interleukin-34. Biochim Biophys Acta. 2015; 1853:1010-21. https://doi.org/10.1016/j. bbamcr.2015.01.023. 
23. Feng ZJ, Gao SB, Wu Y, Xu XF, Hua X, Jin GH. Lung cancer cell migration is regulated via repressing growth factor PTN/RPTP $\beta / \zeta$ signaling by menin. Oncogene. 2010; 29:5416-26. https://doi.org/10.1038/onc.2010.282.

24. Diamantopoulou Z, Kitsou P, Menashi S, Courty J, Katsoris P. Loss of receptor protein tyrosine phosphatase beta/zeta (RPTPbeta/zeta) promotes prostate cancer metastasis. J Biol Chem. 2012; 287: 40339-49.

25. Müller S, Kunkel P, Lamszus K, Ulbricht U, Lorente GA, Nelson AM, von Schack D, Chin DJ, Lohr SC, Westphal $\mathrm{M}$, Melcher T. A role for receptor tyrosine phosphatase zeta in glioma cell migration. Oncogene. 2003; 22:6661-68. https://doi.org/10.1038/sj.onc.1206763.

26. Szatmári T, Ötvös R, Hjerpe A, Dobra K. Syndecan-1 in cancer: implications for cell signaling, differentiation, and prognostication. Dis Markers. 2015; 2015:796052. https:// doi.org/10.1155/2015/796052.

27. Lendorf ME, Manon-Jensen T, Kronqvist P, Multhaupt HA, Couchman JR. Syndecan-1 and syndecan-4 are independent indicators in breast carcinoma. J Histochem Cytochem. 2011; 59:615-29. https://doi. org/10.1369/0022155411405057.

28. Matsuda K, Maruyama H, Guo F, Kleeff J, Itakura J, Matsumoto Y, Lander AD, Korc M. Glypican-1 is overexpressed in human breast cancer and modulates the mitogenic effects of multiple heparin-binding growth factors in breast cancer cells. Cancer Res. 2001; 61:5562-69.

29. Kluger HM, Dolled-Filhart M, Rodov S, Kacinski BM, Camp RL, Rimm DL. Macrophage colony-stimulating factor-1 receptor expression is associated with poor outcome in breast cancer by large cohort tissue microarray analysis. Clin Cancer Res. 2004; 10:173-77. https://doi. org/10.1158/1078-0432.CCR-0699-3.

30. Tamimi RM, Brugge JS, Freedman ML, Miron A, Iglehart JD, Colditz GA, Hankinson SE. Circulating colony stimulating factor-1 and breast cancer risk. Cancer Res. 2008; 68:18-21. https://doi.org/10.1158/0008-5472. CAN-07-3234.

31. Achkova D, Maher J. Role of the colony-stimulating factor (CSF)/CSF-1 receptor axis in cancer. Biochem Soc Trans. 2016; 44:333-41. https://doi.org/10.1042/BST20150245.

32. Charoentong $\mathrm{P}$, Finotello $\mathrm{F}$, Angelova M, Mayer C, Efremova M, Rieder D, Hackl H, Trajanoski Z. Pancancer immunogenomic analyses reveal genotypeimmunophenotype relationships and predictors of response to checkpoint blockade. Cell Reports. 2017; 18:248-62. https://doi.org/10.1016/j.celrep.2016.12.019.

33. Jablonski KA, Amici SA, Webb LM, Ruiz-Rosado JD, Popovich PG, Partida-Sanchez S, Guerau-de-Arellano M. Novel markers to delineate murine M1 and M2 macrophages. PLoS One. 2015; 10:e0145342.

34. Chihara T, Suzu S, Hassan R, Chutiwitoonchai N, Hiyoshi M, Motoyoshi K, Kimura F, Okada S. IL-34 and M-CSF share the receptor Fms but are not identical in biological activity and signal activation. cell death and differentiation. 2010; 17:1917-27.

35. Scholl SM, Pallud C, Beuvon F, Hacene K, Stanley ER, Rohrschneider L, Tang R, Pouillart P, Lidereau R. Anti-colony-stimulating factor-1 antibody staining in primary breast adenocarcinomas correlates with marked inflammatory cell infiltrates and prognosis. J Natl Cancer Inst. 1994; 86:120-26. https://doi.org/10.1093/ jnci/86.2.120.

36. Maher MG, Sapi E, Turner B, Gumbs A, Perrotta PL, Carter D, Kacinski BM, Haffty BG. Prognostic significance of colony-stimulating factor receptor expression in ipsilateral breast cancer recurrence. Clin Cancer Res. 1998; 4:1851-56.

37. Lin EY, Nguyen AV, Russell RG, Pollard JW. Colonystimulating factor 1 promotes progression of mammary tumors to malignancy. J Exp Med. 2001; 193:727-40. https://doi.org/10.1084/jem.193.6.727.

38. Lewis CE, Pollard JW. Distinct role of macrophages in different tumor microenvironments. Cancer Res. 2006; 66:605-12. https://doi.org/10.1158/0008-5472.CAN-05-4005.

39. Jeannin P, Paolini L, Adam C, Delneste Y. The roles of CSFs on the functional polarization of tumor-associated macrophages. FEBS J. 2018; 285:680-99. https://doi. org/10.1111/febs.14343.

40. Mantovani A, Marchesi F, Malesci A, Laghi L, Allavena P. Tumour-associated macrophages as treatment targets in oncology. Nat Rev Clin Oncol. 2017; 14:399-416. https:// doi.org/10.1038/nrclinonc.2016.217.

41. Stanley ER, Chitu V. CSF-1 receptor signaling in myeloid cells. Cold Spring Harbor perspectives in biology. 2014; 6:a021857.

42. Liu H, Leo C, Chen X, Wong BR, Williams LT, Lin H, He $\mathrm{X}$. The mechanism of shared but distinct CSF-1R signaling by the non-homologous cytokines IL-34 and CSF-1. Biochim Biophys Acta. 2012; 1824:938-45. https://doi. org/10.1016/j.bbapap.2012.04.012.

43. Cohen S, Shoshana OY, Zelman-Toister E, Maharshak N, Binsky-Ehrenreich I, Gordin M, Hazan-Halevy I, Herishanu Y, Shvidel L, Haran M, Leng L, Bucala R, Harroch S, Shachar I. The cytokine midkine and its receptor RPTP $\zeta$ regulate B cell survival in a pathway induced by CD74. J Immunol. 2012; 188:259-69. https://doi.org/10.4049/ jimmunol.1101468.

44. Baek JH, Zeng R, Weinmann-Menke J, Valerius MT, Wada Y, Ajay AK, Colonna M, Kelley VR. IL-34 mediates acute kidney injury and worsens subsequent chronic kidney disease. J Clin Invest. 2015; 125:3198-214. https://doi. org/10.1172/JCI81166.

45. Leivonen M, Lundin J, Nordling S, von Boguslawski K, Haglund C. Prognostic value of syndecan-1 expression in breast cancer. Oncology. 2004; 67:11-18. https://doi. org/10.1159/000080280. 
46. Loussouarn D, Campion L, Sagan C, Frenel JS, Dravet F, Classe JM, Pioud-Martigny R, Berton-Rigaud D, Bourbouloux E, Mosnier JF, Bataille FR, Campone M. Prognostic impact of syndecan-1 expression in invasive ductal breast carcinomas. Br J Cancer. 2008; 98:1993-98. https://doi.org/10.1038/sj.bjc.6604400.

47. Beauvais DM, Rapraeger AC. Syndecan-1-mediated cell spreading requires signaling by alphavbeta 3 integrins in human breast carcinoma cells. Exp Cell Res. 2003; 286:219 32. https://doi.org/10.1016/S0014-4827(03)00126-5.

48. Ali HR, Chlon L, Pharoah PDP, Markowetz F, Caldas C. Patterns of immune infiltration in breast cancer and their clinical implications: a gene-expression-based retrospective study. Plos Medicine. 2016; 13:e1002194.

49. Gentles AJ, Newman AM, Liu CL, Bratman SV, Feng W, Kim D, Nair VS, Xu Y, Khuong A, Hoang CD, Diehn M, West RB, Plevritis SK, Alizadeh AA. The prognostic landscape of genes and infiltrating immune cells across human cancers. Nat Med. 2015; 21:938-45. https://doi. org/10.1038/nm.3909.

50. Wang Y, Bugatti M, Ulland TK, Vermi W, Gilfillan S, Colonna M. Nonredundant roles of keratinocyte-derived IL-34 and neutrophil-derived CSF1 in Langerhans cell renewal in the steady state and during inflammation. Eur J Immunol. 2016; 46:552-59. https://doi.org/10.1002/ eji.201545917.

51. Coffelt SB, Kersten K, Doornebal CW, Weiden J, Vrijland K, Hau CS, Verstegen NJM, Ciampricotti M, Hawinkels LJAC, Jonkers J, de Visser KE. IL-17-producing gamma delta $\mathrm{T}$ cells and neutrophils conspire to promote breast cancer metastasis. Nature. 2015; 522:345-8.

52. da Cunha A, Michelin MA, Murta EF. Pattern response of dendritic cells in the tumor microenvironment and breast cancer. World J Clin Oncol. 2014; 5:495-502. https://doi. org/10.5306/wjco.v5.i3.495.

53. Markiewski MM, DeAngelis RA, Benencia F, RicklinLichtsteiner SK, Koutoulaki A, Gerard C, Coukos G, Lambris JD. Modulation of the antitumor immune response by complement. Nat Immunol. 2008; 9:1225-35. https://doi. org/10.1038/ni.1655.

54. Sonnenblick A, Fumagalli D, Sotiriou C, Piccart M. Is the differentiation into molecular subtypes of breast cancer important for staging, local and systemic therapy, and follow up? Cancer Treat Rev. 2014; 40:1089-95. https:// doi.org/10.1016/j.ctrv.2014.07.005.

55. Stampfer MR, Bartley JC. Human mammary epithelial cells in culture: differentiation and transformation. Cancer Treat Res. 1988; 40:1-24. https://doi. org/10.1007/978-1-4613-1733-3_1.

56. Genin M, Clement F, Fattaccioli A, Raes M, Michiels C. M1 and $\mathrm{m} 2$ macrophages derived from THP-1 cells differentially modulate the response of cancer cells to etoposide. BMC cancer. 2015; 15:577.
57. Proestling K, Hebar A, Pruckner N, Marton E, Vinatzer U, Schreiber M. The pro allele of the p53 codon 72 polymorphism is associated with decreased intratumoral expression of BAX and p21, and increased breast cancer risk. PloS One. 2012; 7:e47325.

58. Zins K, Thomas A, Lucas T, Sioud M, Aharinejad S, Abraham D. Inhibition of stromal PlGF suppresses the growth of prostate cancer xenografts. Int J Mol Sci. 2013; 14:17958-71. https://doi.org/10.3390/ijms140917958.

59. Zins K, Schafer R, Paulus P, Dobler S, Fakhari N, Sioud M, Aharinejad S, Abraham D. Frizzled2 signaling regulates growth of high-risk neuroblastomas by interfering with beta-catenin-dependent and beta-catenin-independent signaling pathways. Oncotarget. 2016; 7: 46187-202. https://doi.org/10.18632/oncotarget.10070.

60. Zins K, Gunawardhana S, Lucas T, Abraham D, Aharinejad S. Targeting Cdc42 with the small molecule drug AZA197 suppresses primary colon cancer growth and prolongs survival in a preclinical mouse xenograft model by downregulation of PAK1 activity. J Transl Med. 2013; 11:295. https://doi.org/10.1186/1479-5876-11-295.

61. Li B, Severson E, Pignon JC, Zhao HQ, Li TW, Novak J, Jiang P, Shen H, Aster JC, Rodig S, Signoretti S, Liu JS, Liu XS. Comprehensive analyses of tumor immunity: implications for cancer immunotherapy. Genome Biology. 2016; 17:174.

62. Li T, Fan J, Wang B, Traugh N, Chen Q, Liu JS, Li B, Liu XS. TIMER: A web server for comprehensive analysis of tumor-infiltrating immune cells. Cancer Res. 2017; 77:e108-e110.

63. Yoshihara K, Shahmoradgoli M, Martinez E, Vegesna R, Kim H, Torres-Garcia W, Trevino V, Shen H, Laird PW, Levine DA, Carter SL, Getz G, Stemke-Hale K, et al. Inferring tumour purity and stromal and immune cell admixture from expression data. Nature Communications. $2013 ; 4: 2612$.

64. Harrington DP, Fleming TR. A class of rank test procedures for censored survival-data. Biometrika. 1982; 69:553-66. https://doi.org/10.1093/biomet/69.3.553.

65. Berthon P, Pancino G, de Cremoux P, Roseto A, Gespach C, Calvo F. Characterization of normal breast epithelial cells in primary cultures: differentiation and growth factor receptors studies. In Vitro Cell Dev Biol. 1992; 28A:716-24. https:// doi.org/10.1007/BF02631059.

66. Naryzhny SN, Lee H. Characterization of proliferating cell nuclear antigen (PCNA) isoforms in normal and cancer cells: there is no cancer-associated form of PCNA. FEBS Lett. 2007; 581:4917-20. https://doi.org/10.1016/j. febslet.2007.09.022.

67. Kao J, Salari K, Bocanegra M, Choi YL, Girard L, Gandhi J, Kwei KA, Hernandez-Boussard T, Wang P, Gazdar AF, Minna JD, Pollack JR. Molecular profiling of breast cancer cell lines defines relevant tumor models and provides 
a resource for cancer gene discovery. PloS One. 2009; 4:e6146.

68. Chavez KJ, Garimella SV, Lipkowitz S. Triple negative breast cancer cell lines: one tool in the search for better treatment of triple negative breast cancer. Breast Dis. 2010; 32:35-48. https://doi.org/10.3233/BD-2010-0307.

69. Subik K, Lee JF, Baxter L, Strzepek T, Costello D, Crowley P, Xing L, Hung MC, Bonfiglio T, Hicks DG, Tang P. The expression patterns of ER, PR, HER2, CK5/6, EGFR, Ki-67 and $\mathrm{AR}$ by immunohistochemical analysis in breast cancer cell lines. Breast Cancer (Auckl). 2010; 4:35-41. https:// doi.org/10.1177/117822341000400004.
70. Jiang GL, Zhang SJ, Yazdanparast A, Li M, Pawar AV, Liu YL, Inavolu SM, Cheng LJ. Comprehensive comparison of molecular portraits between cell lines and tumors in breast cancer. Bmc Genomics. 2016; 17:525. https://doi. org/10.1186/s12864-016-2911-z.

71. Parker JS, Mullins M, Cheang MC, Leung S, Voduc D, Vickery T, Davies S, Fauron C, He X, Hu Z, Quackenbush JF, Stijleman IJ, Palazzo J, et al. Supervised risk predictor of breast cancer based on intrinsic subtypes. J Clin Oncol. 2009; 27:1160-67. https://doi.org/10.1200/ JCO.2008.18.1370. 